\title{
Cómo llegar a ser canónigo en el siglo XVI: formas de ingreso en el cabildo de la catedral de Santiago de Compostela*
}

\author{
Arturo IGLesias OrTEGA \\ Archivo Catedralicio de Santiago de Compostela \\ moderna@catedraldesantiago.es
}

Recibido: 12 de abril de 2011

Aceptado: 22 de enero de 2014

\section{RESUMEN}

Este artículo parte del vaciado de las tomas de posesión y de los instrumentos de provisión de los capitulares para detallar las características de las formas de acceso al cabildo catedralicio compostelano del siglo XVI, mediante un análisis estadístico y evolutivo y su comparación con otros cabildos castellanos del período moderno en función de la tipología beneficial. De igual modo, se estudia la problemática de las pensiones, de la acumulación de prebendas y de la promoción interna, así como la vía condicionada entendida como factor de reproducción social y "patrimonialización” de los beneficios capitulares.

Palabras clave: Acumulación de prebendas, cabildos catedralicios, Edad Moderna, "patrimonialización" de beneficios, pensiones, vía condicionada.

\section{How to become a canon in the sixteenth century: ways of access to the cathedral chapter of Santiago de Compostela}

\begin{abstract}
This article is based on takeovers and providing tools to examine in detail the characteristics of the ways of access to the cathedral chapter of Santiago in XVIth century, through statistical and evolutionary analysis and comparison with other Castilian chapters of the Modern Age according to benefice's typology. Similarly, it's studied the questions of pensions, prebends accumulation and internal promotion, as well as conditional way as a factor of social reproduction and inheritability of chapter benefices.
\end{abstract}

Key words: Benefices inheritability, cathedral chapters, conditional way, Modern Age, pensions, prebends accumulation.

\footnotetext{
* Este trabajo ha sido financiado dentro del proyecto de investigación "Cultura e identidades urbanas en la Castilla Moderna, su producción y proyecciones" (HAR2009-13508-C02-02/HIST), dirigido por la Dra. Ofelia Rey Castelao.
} 


\section{Introducción: la casuística}

El estudio de las formas de acceso a los cabildos catedralicios puede hacerse en función del sistema de provisión y elección: de forma resumida, podemos decir que el nombramiento de prebendas capitulares compostelanas en el siglo XVI recayó en sus dos terceras partes en la Santa Sede, fundamentalmente por vía de reserva apostólica; el otro tercio correspondió a la Iglesia de Santiago, esto es, al arzobispo y cabildo por elección simultánea (canonjías y raciones) o por vía de oposición (canonjías de oficio), al arzobispo en solitario por vía ordinaria (dignidades) y por alternativa apostólica (canonjías), al cabildo en solitario (sede vacante) y al deán en solitario (lectoral de Decretos); finalmente, aunque su capacidad de influencia fue mayor, la Corona designaba al prior de Sar vía patronato real y a algún capitular por indulto apostólico ${ }^{1}$. Pero el acceso a los cabildos también puede estudiarse en función de otros criterios: el objetivo del trabajo que aquí presentamos es analizar estadísticamente las formas de ingreso del cabildo catedralicio de Santiago en el siglo XVI teniendo en cuenta las formas en que vacaban las prebendas y sus motivaciones, y comparando sus resultados con los ofrecidos por otros trabajos similares sobre cabildos catedralicios. Para ello hemos vaciado, por un lado, las tomas de posesión de los 492 capitulares que hemos logrado individualizar, algunas de las cuales transcriben los títulos ordinarios y bulas de provisión originales, registradas en las actas capitulares del Archivo Catedralicio de Santiago (ACS) y, supletoriamente, en alguno de los protocolos notariales compostelanos de ese mismo archivo o del Arquivo Histórico Universitario de Santiago (AHUS); y, por otro, las bulas de provisión custodiadas en el Archivio Segreto Vaticano (ASV). En cuanto a la metodología comparativa, aunque existe una cada vez más abundante bibliografía sobre cabildos catedralicios, interesada sobre todo en aspectos sociales y sociológicos ${ }^{2}$, apenas se han publicado trabajos sobre bases estadísticas amplias y fiables, de ahí que en este artículo hayamos manejado únicamente los datos ofrecidos en dos publicaciones referidas a cabildos que, como el santiagués, no eran de patronato real ${ }^{3}$.

De manera general, dejando al margen los beneficiados que accedían por erección de un beneficio nuevo (caso, por ejemplo, del priorato de Santiago), un individuo sólo podía acceder a un beneficio que hubiese perdido su anterior beneficiado ${ }^{4}$. La pérdida solía producirse por alguna de las siguientes causas:

1 Véase Iglesias Ortega, A.: La catedral de Santiago de Compostela y sus capitulares: funcionamiento y sociología de un cabildo en el siglo XVI, A Coruña, Diputación de A Coruña, 2012, pp. 283-305.

2 Véase, por ejemplo, MARín López, R.: "Historiografía sobre cabildos eclesiásticos. Estado de la cuestión y perspectivas de investigación”, en Cortés PeÑA, A. L. y López-Guadalupe Muñoz, M. L. (eds.): La Iglesia española en la Edad Moderna. Balance historiográfico y perspectivas, Madrid, Abada Editores, 2007, pp. 75-112.

3 Se trata de Irigoyen López, A.: Entre el cielo y la tierra, entre la familia y la institución. El cabildo de la catedral de Murcia en el siglo XVII, Murcia, Universidad de Murcia, 2000; y VÁzQuez Lesmes, R.: Córdoba y su cabildo catedralicio en la Modernidad, Córdoba, Publicaciones de la Caja de Ahorros y Monte de Piedad de Córdoba, 1987.

4 Incluso cuando se producía la supresión, extinción o anexión de un beneficio para dotar o crear otro (caso, por ejemplo, de las canonjías de oficio y maestro de capilla de Santiago), esto se hizo a partir de beneficios que habían vacado por muerte (por ejemplo, la doctoralía, la magistralía y la lectoralía de Sagrada Escritura), renuncia (la lectoralía de Decretos), resigna (el magisterio de capilla) o privación (la penitenciaría) del titular. 
$1^{\text {a) }}$ Por muerte del beneficiado.

$2^{\mathrm{a}}$ ) Por privación judicial, administrativa o disciplinal, de acuerdo a lo dispuesto en la legislación canónica, como cuando vacaban todos los beneficios de un clérigo que es promovido a un obispado o ante la comisión por parte del beneficiado de ciertos delitos.

$3^{\mathrm{a}}$ ) Por voluntad del beneficiado, que se produce en los casos de dimisión, resigna en favor y permuta.

$\left.4^{a}\right)$ Por traslación, que puede ser del beneficio (con autoridad del ordinario: por ejemplo, la mutación del título de juez de Villestro al de arcediano de Santiago) o del beneficiado (de un oficio eclesiástico a otro, o de una iglesia a otra). A su vez, la traslación puede ser voluntaria, por lo que habría que considerarla en el apartado anterior, o forzosa, por imposición del superior ordinario.

En principio, la pérdida del beneficio suponía su vacante, dado que quedaba sin ocupar hasta su nueva provisión. Sin embargo, existía la posibilidad de acceder a un beneficio sin que este hubiese vacado, mediante un derecho de futura sucesión, es decir, por una expectativa o una coadjutoría, formas que consideraremos por su especial significación, pero siempre teniendo en cuenta que, en ambos casos, el acceso venía determinado, en la mayor parte de las ocasiones, por el fallecimiento del titular ${ }^{5}$. Por lo que a este trabajo se refiere, se han estudiado únicamente los capitulares posesionados en sus prebendas, es decir, los capitulares de hecho, independientemente de que también lo fueran de derecho (beneficiados de pleno derecho) o no (beneficiados intrusos). Esto es importante porque no siempre el antecesor de hecho coincide con el antecesor de derecho y, por tanto, las causas de sucesión varían en uno u otro caso.

La terminología empleada es muy variada y a veces confusa. En derecho canónico se habla de resignación o resigna, renunciación o renuncia, dejación, dimisión, cesión, amisión, traslación, promoción, etc. Centrándonos en las vacantes por voluntad del beneficiado, podemos decir que cuando un beneficiado hacía dejación o renuncia de su beneficio, esta podía ser de dos maneras ${ }^{6}$ :

$1^{\text {a }}$ ) dimisión o dejación pura y simple hecha por el titular en manos del colador para que dispusiese del beneficio en favor del que le pareciese ${ }^{7}$.

$2^{\mathrm{a}}$ ) resignación o dejación hecha por el titular en manos del colador, con la condición de que dispusiese del beneficio en provecho de quien él señalase (resignación condicional). Esta última suele referirse exclusivamente a la resigna en favor, pero

5 Los canonistas suelen considerar vacantes solamente a las de hecho y de derecho (cuando nadie posee el beneficio ni tiene derecho a él: por ejemplo, por muerte y dimisión), de manera que las resignas y permutas, así como las vacantes por muerte o resigna de intrusos, no pueden considerarse vacantes en puridad.

6 Datos extraídos a partir de Teruel Gregorio De Tejada, M.: Vocabulario básico de la Historia de la Iglesia, Barcelona, Crítica, 1993, p. 21; André, M. (Abbé): Diccionario de Derecho Canónico, traducido del que ha escrito en francés el Abate Andrés, arreglado a la jurisprudencia eclesiástica española antigua y moderna, Madrid, Imprenta de D. José C. de la Peña, t. I (1847), pp. 303-307; t. II (1847), pp. 194-197; t. IV (1848), pp. 262-263, 324-328 y 336-337; Enciclopedia Universal Ilustrada Europea-Americana, Madrid, Espasa-Calpe, 1991-1994, 72 vols. (voces “beneficio”, “coadjutor”, “dejación”, “dimisión”, "resigna”, "traslación", "vacante").

7 Existen dos tipos de dimisiones: la expresa o voluntaria, nacida puramente de motivos personales apreciados por el dimitente; y la tácita u obligada, producida por los diferentes casos que la ley y la autoridad determinan para hacer vacar un beneficio (privación). 
también se podría incluir en esa tipología a las renuncias (dimisiones o resignas) con reserva de pensión sobre el beneficio renunciado, con reserva de frutos o con regreso, acceso e ingreso al mismo, por permuta o por promoción a un beneficio superior.

Como ya se ha indicado, la terminología registrada en las fuentes documentales es a veces imprecisa, cuando no contradictoria, a la hora de identificar las causas de sucesión. No hay ninguna duda en cuanto a las vacantes por muerte del antecesor, ni en cuanto a las sucesiones por expectativa o coadjutoría. El problema surge cuando tratamos de cualquier tipo de dejación: las dos fuentes de información principales son las actas capitulares y la documentación pontificia. Las actas no siempre insertan traslados de los instrumentos colativos, de manera que debemos jugar con expresiones tan genéricas como "renunciación" o "renuncia", "resignación" o "resigna" (a favor o no de alguien), o "dejación", a veces combinados (resignación y renunciación, por ejemplo), y muchas veces acompañados por los adjetivos "libre" (exenta de coacción), "pura" (por tratarse de un acto legítimo) y/o "simple". Este último permitiría identificar a las dimisiones, pues, teóricamente, son renuncias simples y no condicionadas, pero, a pesar de ello, encontramos ejemplos de capitulares que en las actas capitulares accedieron por simple resignación o renunciación, pero que en las bulas pontificias se dice lo hicieron por libre resignación.

En cuanto a la documentación pontificia, es habitual la expresión "libre cesión", referida a las dimisiones, frente a la de "libre resignación", teóricamente identificable con las resignaciones en favor. Sin embargo, no es fácil seguirle la pista a estas últimas: el derecho canónico no recoge apenas nada relacionado directamente con ellas $\mathrm{y}$, en la práctica, fueron renuncias puras y simples únicamente identificables desde que, a finales del siglo XIV o comienzos del XV, se empezaron a insertar en las dimisiones súplicas del resignante en favor de otros. En 1549 se suprimió todo lo que podía caracterizar una dimisión pura y simple y ya no se pusieron súplicas, sino que sólo se decía en las procuraciones ad resignandum in manus ect. in favorem tamen ${ }^{8}$. Esto quiere decir que, si queremos encontrar un indicativo claro de tal resigna, no es suficiente con leer la bula de provisión de la prebenda, sino que hay que acudir directamente a la súplica del resignante o su procurador ${ }^{9}$. Desgraciadamente, no hemos podido consultar los registros de súplicas del Archivio Segreto Vaticano, con lo que las identificaciones serán menos seguras.

¿Y qué sucede con las traslaciones voluntarias? En ningún documento hemos hallado esa palabra. Normalmente se habla de "dejación por promoción", "resigna a favor por promoción", "remisión y promoción", etc., incidiendo en su propio carácter de renuncia deliberada. Lo que ocurre es que, aunque no se indique, muchas veces podemos deducir que se produce una traslación encubierta en casos de simples dimisiones, bien por promoción (cuando se accede, por ejemplo, a otra prebenda de la misma catedral), bien por permuta (cuando el sucesor en la prebenda que deja es el antecesor en la que toma).

\footnotetext{
8 ANDRÉ, op. cit. (nota 6), t. IV, p. 263.

9 Sobre las súplicas, véase Domínguez SÁnchez, S.: "Seis súplicas leonesas del siglo XVI. Estudio diplomático”, Espacio, Tiempo y Forma. Serie IV. Historia Moderna, 9 (1996), pp. 157-178.
} 
Por su parte, los ejemplos de privación de beneficio no son fácilmente identificables: los recogidos en este trabajo están relacionados en su inmensa mayoría con el empleo de medios ilícitos para obtener una prebenda (subrepticia y obrepticiamente), la incompatibilidad de beneficios, la falta de órdenes sacras necesarias o el acceso al estado civil para poder tomar matrimonio. En muchos de estos casos, la documentación indica que los nuevos capitulares suceden a los intrusos o son privados de su prebenda por la relajación, dejación o apartamiento de su derecho a la misma, por amisión (pérdida), o, simplemente, por su renuncia o resigna, por lo que pueden ser consideradas dimisiones obligadas. En otros casos, los sucesores hacen valer sus instrumentos colativos para desplazar al intruso de la posesión de su prebenda, de modo que la causa de derecho es la que figura en aquellos.

\section{Análisis de los datos}

\subsection{Estudio comparado de las formas de ingreso}

Cuando es posible, hemos optado por señalar en las tablas analíticas las siguientes modalidades de acceso a una prebenda capitular: por defunción, por privación, por dimisión voluntaria (vía institucional), por regreso, por resigna, por permuta, por traslación, por expectativa y por coadjutoría (vía condicionada).

Tabla 1. Formas de acceso al cabildo compostelano (siglo XVI) ${ }^{10}$

\begin{tabular}{|c|c|c|c|c|c|}
\hline \multirow{2}{*}{\multicolumn{2}{|c|}{ FORMAS DE ACCESO }} & \multicolumn{4}{|c|}{ PREBENDADOS } \\
\hline & & \multicolumn{2}{|c|}{ 1564-1599 } & \multicolumn{2}{|c|}{ 1500-1599 } \\
\hline & & $\mathrm{n}^{\mathbf{0}}$ & $\%$ & $\mathrm{n}^{\mathbf{0}}$ & $\%$ \\
\hline \multirow{4}{*}{ Vía institucional } & Muerte & 83 & 46,63 & 227 & 33,68 \\
\hline & Dimisión & 5 & 2,81 & 27 & 4,01 \\
\hline & Privación & 3 & 1,69 & 8 & 1,19 \\
\hline & Total & 91 & 51,12 & 262 & 38,87 \\
\hline \multicolumn{2}{|l|}{ Dimisión/resigna } & 5 & 2,81 & 47 & 6,97 \\
\hline \multirow{8}{*}{ Vía condicionada } & Resigna & 23 & 12,92 & 131 & 19,44 \\
\hline & Coadjutoría & 26 & 14,61 & 79 & 11,72 \\
\hline & Permuta & 13 & 7,30 & 36 & 5,34 \\
\hline & Regreso & 6 & 3,37 & 20 & 2,97 \\
\hline & Traslación & 5 & 2,81 & 11 & 1,63 \\
\hline & Expectativa & 0 & 0 & 8 & 1,19 \\
\hline & \begin{tabular}{|l|} 
Erección \\
\end{tabular} & 0 & 0 & 1 & 0,15 \\
\hline & Total & 73 & 41,01 & 286 & 42,43 \\
\hline \multicolumn{2}{|l|}{ Se ignora } & 5 & 2,81 & 79 & 11,72 \\
\hline \multicolumn{2}{|l|}{ Total } & 178 & 100 & 674 & 100 \\
\hline
\end{tabular}

10 La tabla 1 se refiere a todos los capitulares que vivieron durante la decimosexta centuria, incluidos los que accedieron en la anterior. 
Tabla 2. Formas de acceso al cabildo de Córdoba (1564-1700) ${ }^{11}$

\begin{tabular}{|c|c|c|c|c|c|}
\hline \multirow{2}{*}{\multicolumn{2}{|c|}{ FORMAS DE ACCESO }} & \multicolumn{4}{|c|}{ PREBENDADOS } \\
\hline & & \multicolumn{2}{|c|}{$1564-1600$} & \multicolumn{2}{|c|}{ Siglo XVII } \\
\hline & & $n^{0}$ & $\%$ & $n^{0}$ & $\%$ \\
\hline \multirow{3}{*}{ Vía institucional } & Muerte y otros & $38 ?$ & 44,19 & $121 ?$ & 47,83 \\
\hline & Dimisión & 0 & 0 & 0 & 0 \\
\hline & Total & $38 ?$ & 44,19 & $121 ?$ & 47,83 \\
\hline \multirow{4}{*}{ Vía condicionada } & Coadjutoría & 11 & 12,79 & 98 & 38,74 \\
\hline & Resigna & 5 & 5,81 & 27 & 10,67 \\
\hline & \begin{tabular}{|l|} 
Permuta \\
\end{tabular} & 2 & 2,33 & 0 & 0 \\
\hline & Total & 18 & 20,90 & 125 & 49,41 \\
\hline \multicolumn{2}{|l|}{ Se ignora } & $30 ?$ & 34,88 & $7 ?$ & 2,77 \\
\hline \multicolumn{2}{|l|}{ Total } & 86 & 100 & 253 & 100 \\
\hline
\end{tabular}

Tabla 3. Formas de acceso al cabildo de Murcia (1600-1700) $)^{12}$

\begin{tabular}{|c|c|c|c|c|c|c|c|c|c|c|c|}
\hline \multirow{3}{*}{\multicolumn{2}{|c|}{$\begin{array}{l}\text { FORMAS DE } \\
\text { ACCESO }\end{array}$}} & \multicolumn{10}{|c|}{ PREBENDADOS } \\
\hline & & \multicolumn{2}{|c|}{ Dignidades } & \multicolumn{2}{|c|}{ Canónigos } & \multicolumn{2}{|c|}{$\begin{array}{c}\text { Canónigos } \\
\text { oficio }\end{array}$} & \multicolumn{2}{|c|}{ Racioneros } & \multicolumn{2}{|c|}{ Total } \\
\hline & & $n^{0}$ & $\%$ & $n^{0}$ & $\%$ & $n^{0}$ & $\%$ & $n^{0}$ & $\%$ & $n^{0}$ & $\%$ \\
\hline \multirow{3}{*}{$\begin{array}{l}\text { Vía } \\
\text { institucional }\end{array}$} & \begin{tabular}{|l|}
$\begin{array}{l}\text { Muerte y } \\
\text { otros }\end{array}$ \\
\end{tabular} & 18 & 40,91 & 10 & 40 & 27 & 93,10 & 29 & 50,88 & 84 & 54,19 \\
\hline & \begin{tabular}{|l|} 
Dimisión \\
\end{tabular} & 0 & 0 & 0 & 0 & 0 & 0 & 0 & 0 & 0 & 0 \\
\hline & Total & 18 & 40,91 & 10 & 40 & 27 & 93,10 & 29 & 50,88 & 84 & 54,19 \\
\hline \multirow{4}{*}{$\begin{array}{l}\text { Vía } \\
\text { condicionada }\end{array}$} & Coadjutoría & 15 & 34,09 & 11 & 44 & 2 & 6,90 & 15 & 26,32 & 43 & 27,74 \\
\hline & Resigna & 9 & 20,45 & 4 & 16 & 0 & 0 & 10 & 17,54 & 23 & 14,84 \\
\hline & Permuta & 2 & 4,55 & 0 & 0 & 0 & 0 & 3 & 5,26 & 5 & 3,23 \\
\hline & Total & 26 & 59,09 & 15 & 60 & 2 & 6,90 & 28 & 49,12 & 71 & 45,81 \\
\hline Total & & 44 & 100 & 25 & 100 & 29 & 100 & 57 & 100 & 155 & 100 \\
\hline
\end{tabular}

La tabla 1 refleja las distintas modalidades de acceso de los prebendados de Santiago que vivieron en el siglo XVI. Para realizar una comparación, a pesar de la carencia de trabajos estadísticos sobre cabildos similares del mismo período, hemos elaborado unas tablas con los datos referentes a Córdoba y Murcia (tablas 2 y 3), recogidos, respectivamente, en los estudios de Vázquez Lesmes e Antonio Irigoyen y centrados en el siglo XVII, lo que, al menos, nos permitirá plantear un análisis evolutivo. Dado que Vázquez Lesmes recoge separadamente los datos relativos al cabildo

11 Elaboración propia a partir de los datos aportados por VÁZQUEZ LESMES, op. cit. (nota 3), pp. 61 y 75.

12 Elaboración propia a partir de los datos aportados por IRIGOYEN LÓPEZ, op. cit. (nota 3), pp. 38-39. El autor incluye las canonjías de oficio en el grupo general de canonjías, pero yo señalo entre paréntesis los porcentajes referidos únicamente a los canónigos "atitulados". 
cordobés del período 1564-1600 (si bien, manejando únicamente 86 casos), también hemos incluido los concernientes al compostelano de la misma época. En cualquier caso, los datos ofrecidos en estas dos últimas tablas son orientativos, puesto que en dichos trabajos se dan sólo las cifras de acceso por dimisiones, resignas, permutas y coadjutorías, de manera que hemos deducido que el resto (lo que Antonio Irigoyen considera provisiones por vacantes, realizadas por las instituciones), correspondería, fundamentalmente, a sucesiones por muerte. Además, hay que tener en cuenta que el caso cordobés se basa casi exclusivamente en los expedientes de limpieza de sangre, que el número de casos desconocidos es notable para el siglo XVI (probablemente unas tercera parte del total) y que hemos deducido las cifras de sucesiones "por muerte y otros" a partir de los comentarios del autor.

Dicho esto, podemos señalar, en primer lugar, que los capitulares compostelanos del XVI ingresaron en el cabildo por distintos caminos, siendo la vacante por defunción la más importante $\left(33,68 \% ; 38,15 \%\right.$, si descartamos los casos desconocidos) ${ }^{13}$. Sumando los casos que emplearon otros cauces aparentemente no susceptibles de abusos (vía institucional), el porcentaje se eleva hasta el 39\% (44\%, si descartamos los desconocidos), bastante por debajo de los valores de los otros dos cabildos para la centuria siguiente, sin tener en cuenta los casos desconocidos (Murcia: 54\%; Córdoba: $49 \%$ ). Esos otros cauces son la dimisión (4\%) y la privación (poco más del $1 \%)$. El escaso porcentaje de dimisiones registradas demuestra que las renuncias sin ninguna condición eran poco frecuentes (en los ejemplos cordobés y murciano no se registra ningún caso). Los casos rastreados de privación se refieren a dejaciones por comisión apostólica o del Tribunal de la Rota en pleitos por la posesión de la prebenda (4), falta de promoción a las órdenes exigidas (2), simonía (1) y despido por no residir el beneficio (1). Por supuesto, hubo muchísimos más litigios por las prebendas, pero en el resto se registraron como causa de sucesión los derechos de acceso del que finalmente las obtuvo o acabaron con acuerdos entre las partes.

Por otro lado, se observa el predominio general de las modalidades de acceso a instancias del futuro beneficiado, es decir, la vía condicionada $(42,43 \% ; 48,07 \%$ descartando los ignorados), entre las que destacan las resignas, las coadjutorías y las permutas. A diferencia de los ejemplos cordobés y murciano, en los que las coadjutorías destacan sobremanera por encima de las resignas (39\% frente al $11 \%$ en todo el XVII para el cabildo cordobés; $28 \%$ frente al $15 \%$ en el XVII para el cabildo murciano), el cabildo de Santiago se caracteriza por un predominio de las resignas: un $22 \%$ frente a más del 13\% de las coadjutorías (descartados los ignorados). Esta diferencia sería aún mayor si tenemos en cuenta que hubo un $8 \%$ de casos de renunciaciones sin identificar, de los que la mayor parte debieron de ser resignas a favor, y que hemos contabilizado tanto a los coadjutores $(5,49 \%)^{14}$ como a los que finalmente sucedieron en la titularidad de la prebenda en virtud de bulas de coadjutoría, que incluyen a casi todos los anteriores más aquellos que no llegaron a ejercer como coadjutores $(6,23 \%)$. Es

13 Si considerásemos los casos en que los coadjutores suceden a los propietarios de las prebendas por su fallecimiento, el porcentaje se situaría cerca del $38 \%$ o por encima del $43 \%$, descartando los casos desconocidos.

14 Hemos localizado un total de 37 coadjutores, de los que 24 lo fueron de canónigos $(64,86 \%), 12$ de dignidades $(32,43 \%)$ y 1 de racioneros $(2,70 \%)$. De todos ellos, únicamente 5 no llegaron a ser titulares de la prebenda y 3 lo fueron en el siglo XVII. 
decir, habida cuenta de que tanto los capitulares titulares como sus coadjutores coexistieron a un mismo tiempo, hemos considerado a estos últimos como un estadio inferior y distinto al que obtendrían tiempo después accediendo a la plena propiedad de la prebenda. En cuanto a las permutas, su porcentaje $(5,34 \%)$ se sitúa en valores algo superiores respecto al caso murciano (4\%) y cordobés $(2,33 \%)$.

El ejemplo compostelano ofrece otras formas minoritarias dentro de la vía condicionada: la primera, la de los regresos (2,97\%), que se activaron por fallecimiento del titular que había obtenido en su día la prebenda a cambio del regreso a favor de su sucesor; la segunda, la de las traslaciones $(1,63 \%)$, semejantes a las permutas, recoge los casos de promoción a otras prebendas del cabildo compostelano (7) o a obispados (3), y los de mutación de una prebenda por otra (el juzgado de Villestro por el arcedianato de Santiago en 1531); la tercera, la de las expectativas (1,19\%), similares a las coadjutorías, se concentra en las primeras décadas del período estudiado, incluyendo las últimas décadas del siglo XV hasta 1530, dado que el Concilio de Trento las prohibió terminantemente; la cuarta, la de la erección ex novo de beneficios $(0,15 \%)$, se corresponde con la creación en 1530 de la dignidad de priorato de Santiago a petición del canónigo Juan de Lemos.

Gráfico 1. Evolución anual del número de capitulares en función de su forma de acceso (1500-1599)

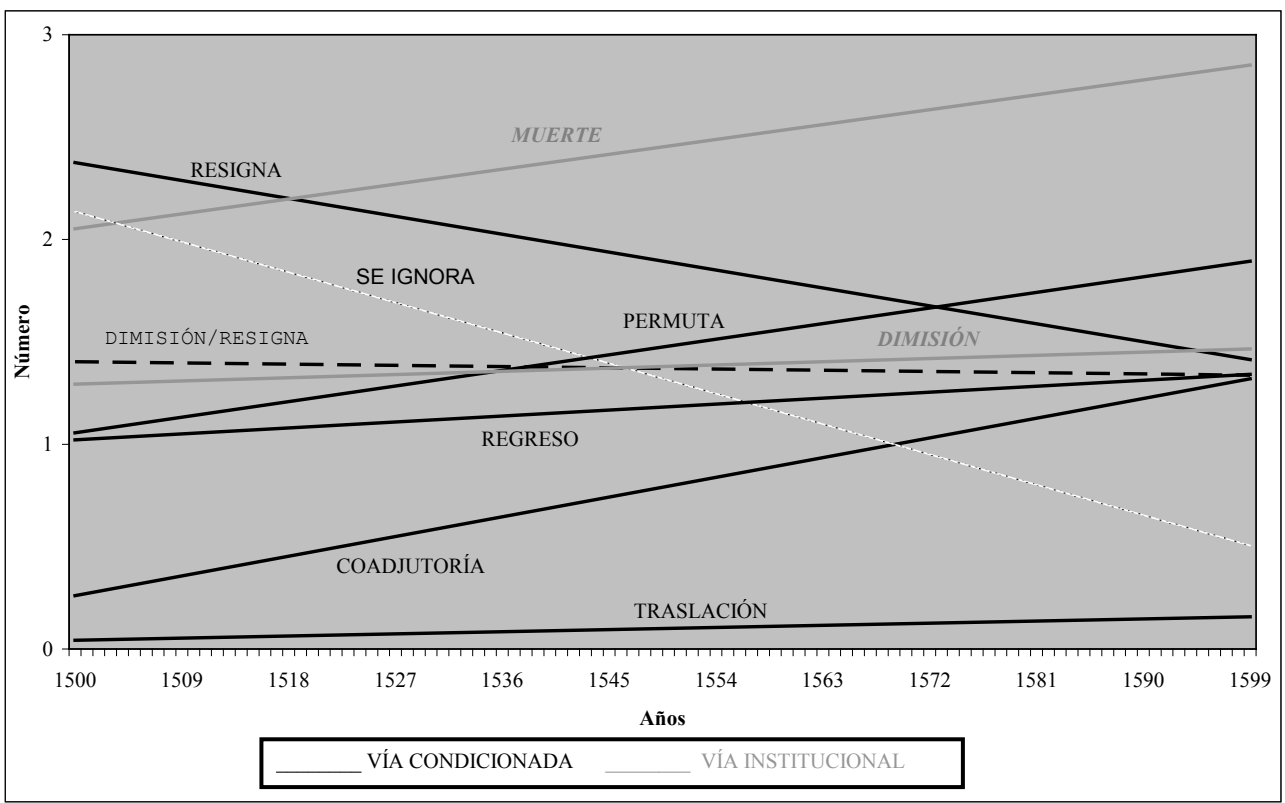

La observación de la evolución de los valores de estas principales vías de acceso en el caso compostelano (gráfico 1) y el cotejo con los datos referidos al período 15641599 (tabla 1) nos permite suponer que la situación en este cabildo fue más semejante a la de otros cabildos durante el Seiscientos, puesto que se produce un incremento 
de las permutas y, sobre todo, de las coadjutorías frente al descenso de las resignas, relacionado con el endurecimiento en Roma de los requisitos para su concesión y su altísimo coste ${ }^{15}$. Sin embargo, a pesar de ese incremento de las coadjutorías, las resignas siguen teniendo un altísimo peso, incluso en las últimas décadas de la centuria (15\%-13\% para Santiago frente al 20\%-9\% para Córdoba, descontados los casos desconocidos), debido a la mayor importancia que en el cabildo compostelano tuvo el componente no local y foráneo, a diferencia de los cabildos cordobés y murciano. Por otra parte, el incremento de las sucesiones por defunción estaría relacionado con el desarrollo de las canonjías de oficio durante la segunda mitad de la centuria.

Tabla 4. Formas de de acceso al cabildo. Valores en función de la prebenda

\begin{tabular}{|l|l|l|l|l|l|l|l|l|l|l||}
\hline \multirow{2}{*}{$\begin{array}{l}\text { FORMAS DE } \\
\text { ACCESO }\end{array}$} & \multicolumn{10}{|c|}{ PREBENDADOS } \\
\cline { 2 - 13 } & \multicolumn{2}{|c|}{ Dignidades } & \multicolumn{2}{|c|}{ Canónigos } & \multicolumn{2}{c|}{ C. Oficio } & \multicolumn{2}{c|}{ Racioneros } & \multicolumn{2}{c||}{ Total } \\
\cline { 2 - 13 } & $\mathbf{n}^{\mathbf{0}}$ & $\mathbf{\%}$ & $\mathbf{n}^{\mathbf{0}}$ & $\mathbf{\%}$ & $\mathbf{n}^{\mathbf{0}}$ & $\mathbf{\%}$ & $\mathbf{n}^{\mathbf{0}}$ & $\mathbf{\%}$ & $\mathbf{n}^{\mathbf{0}}$ & $\mathbf{\%}$ \\
\hline Muerte & 69 & 37,91 & 112 & 31,73 & 19 & 67,86 & 27 & 24,32 & 227 & 33,68 \\
\hline Dimisión & 8 & 4,40 & 14 & 3,97 & 0 & 0 & 5 & 4,50 & 27 & 4,01 \\
\hline Privación & 2 & 1,10 & 2 & 0,57 & 3 & 10,71 & 1 & 0,90 & 8 & 1,19 \\
\hline $\begin{array}{l}\text { Dimisión/ } \\
\text { resigna }\end{array}$ & 8 & 4,40 & 23 & 6,52 & 1 & 3,57 & 15 & 13,51 & 47 & 6,97 \\
\hline Resigna & 37 & 20,33 & 76 & 21,53 & 3 & 10,71 & 15 & 13,51 & 131 & 19,44 \\
\hline Coadjutoría & 24 & 13,19 & 53 & 15,01 & 0 & 0 & 2 & 1,80 & 79 & 11,72 \\
\hline Permuta & 10 & 5,49 & 17 & 4,82 & 1 & 3,57 & 8 & 7,21 & 36 & 5,34 \\
\hline Regreso & 3 & 1,65 & 16 & 4,53 & 0 & 0 & 1 & 0,90 & 20 & 2,97 \\
\hline Traslación & 4 & 2,20 & 3 & 0,85 & 1 & 3,57 & 3 & 2,70 & 11 & 1,63 \\
\hline Expectativa & 3 & 1,65 & 5 & 1,42 & 0 & 0 & 0 & 0 & 8 & 1,19 \\
\hline Erección & 1 & 0,55 & 0 & 0 & 0 & 0 & 0 & 0 & 1 & 0,15 \\
\hline Se ignora & 13 & 7,14 & 32 & 9,07 & 0 & 0 & 34 & 30,63 & 79 & 11,72 \\
\hline \hline Total & 182 & 100 & 353 & 100 & 28 & 100 & 111 & 100 & 674 & 100 \\
\hline \hline
\end{tabular}

La observación de los datos en función de la tipología beneficial nos permite profundizar en su análisis (tabla 4). Podemos, además, realizar la comparación con los resultados ofrecidos por Antonio Irigoyen para el cabildo murciano en el siglo XVII (tabla 3). En primer lugar, debemos señalar que, en lo que a las raciones se refiere, nos enfrentamos a un $31 \%$ cuya forma de acceso nos es desconocida. De los 34 casos desconocidos, 9 son posteriores a 1519 y sólo 4 a 1544. Estas dos fechas son reseñables porque explican perfectamente esta ausencia de información en las actas capitulares: en 1519 se registra la primera toma de posesión de un racionero compostelano y en 1544 se acuerda que nadie pudiese dar posesión de ninguna ración sin que su provisión apostólica u ordinaria fuese presentada y examinada por el cabildo, y sin que este mandase hacerlo del mismo modo que con las dignidades y canónigos.

15 Irigoyen LóPez, op. cit. (nota 3), pp. 66-67. El motivo fue la prohibición tridentina de proveer prebendas no vacantes (CABeza, A.: Clérigos y señores. Política y religión en Palencia en el Siglo de Oro, Palencia, Diputación Provincial de Palencia, 1996, p. 252). 
Para poder igualar los márgenes de error entre todas las tipologías capitulares, hemos decidido considerar los porcentajes excluyendo los elementos no conocidos. Veamos uno a uno todos los grupos capitulares:

Por lo que toca a las dignidades, el porcentaje de las que acceden por la vía condicionada se mueve entre un $48,52 \%$ y un $53,25 \%$, según si añadimos el grupo de dimisiones/resignas. El 46,75\% restante correspondería a la vía de acceso institucional. En el caso de Murcia ocurre algo similar, pero lo que aquí es una ligera tendencia, allí es un claro desequilibrio $(59 \%$ frente al 41\%). Además, mientras allí se imponen las coadjutorías (34\%) a las resignas (23\%), aquí predominan claramente las resignas $(21,89 \%)$ sobre las coadjutorías $(14,20 \%)$ por los motivos aducidos anteriormente.

- $\quad$ En cuanto a las canonjías, aquí es muy patente el desequilibrio a favor de la vía condicionada por el capitular $(52,29 \%$ ó 59,88\%, considerando las dimisiones/resignas) frente a la vía institucional (40,12\%), debido al alto número de regresos, que inclinan la balanza a favor de la primera. Coincide, en este caso, con lo ocurrido en Murcia, donde, a diferencia de Compostela -en la cual se repite la misma situación que en las dignidades-, vuelven a predominar las resignas sobre las coadjutorías (44\% frente al 16\%).

- Respecto a las canonjías de oficio, mayoritariamente provistas mediante oposición, se impone claramente la vía institucional (78,57\%), fundamentalmente por muerte del antecesor, frente a la condicionada $(17,86 \%$ ó $21,43 \%$, si añadimos las renuncias sin especificar). El estudio sobre Murcia indica el acceso de estos canónigos mediante oposición, salvo dos casos en que se accedió por coadjutoría, lo que nos hace suponer que la causa de la vacante en la mayoría fue muerte o dimisión, es decir, por la vía institucional.

En el caso de las raciones compostelanas, por su parte, la balanza se inclina hacia una $u$ otra forma de acceso si tenemos o no en cuenta el cuantioso grupo de dimisiones/resignas: la vía condicionada pasaría de un 37,66\% a un $57,14 \%$, frente al $42,86 \%$ de la vía institucional, sin tener en cuenta el elevado número de casos desconocidos. Esta variación porcentual tan marcada no nos permite afirmar con rotundidad cuál es la vía predominante, pero, dado que el papel de Roma en la colación de raciones es menor que en el caso de las dignidades y canonjías, podemos deducir un peso superior de la vía institucional. Nuevamente se observa un predominio de las resignas frente a las coadjutorías, que aquí son prácticamente inexistentes, a diferencia del modelo murciano, donde, además, se registra un equilibrio entre las dos formas de acceso por lo que a las raciones toca.

\subsection{Prebendas libres y prebendas apensionadas}

Para completar este análisis, hemos elaborado una tabla sobre las pensiones que cargaban algunas prebendas capitulares, teniendo en cuenta el tipo de prebenda y la vía de acceso del capitular a la misma (tabla 5). Aunque no se trata, ni mucho menos, de un registro completo de todas las pensiones existentes, es lo suficientemente significativo. Podemos apreciar que, al menos un $15 \%$ de todas ellas, eran apensionadas. 
La permuta y la resigna eran las vías de acceso más susceptibles de conllevar una pensión sobre la prebenda. Como ya hemos indicado anteriormente, el porcentaje de prebendados que accedieron mediante esas vías fue del $24 \%$, por lo que, si ese $15 \%$ correspondiese a estos prebendados, estaríamos ante un gran mayoría de casos. Sin embargo, lo más interesante es que más de la mitad de ese $15 \%$ se refiere a prebendados que accedieron por la vía teóricamente institucional (si bien se han incluido aquí los casos de dimisiones/resignas). Esto demuestra que, en la práctica, hubo un menor número de prebendas "libres" de lo que la forma de acceso indica, sobre todo en el caso de las canonjías.

Tabla 5. Prebendados compostelanos cuya prebenda estuvo cargada con alguna pensión

\begin{tabular}{|c|c|c|c|c|c|c|c|c|c|c|c|}
\hline \multirow{3}{*}{\multicolumn{2}{|c|}{ VÍA ACCESO }} & \multicolumn{10}{|c|}{ PREBENDADOS } \\
\hline & & \multicolumn{2}{|c|}{ Dignidades } & \multicolumn{2}{|c|}{ Canónigos } & \multicolumn{2}{|c|}{ C. Oficio } & \multicolumn{2}{|c|}{ Racioneros } & \multicolumn{2}{|c|}{ Total } \\
\hline & & $\mathrm{n}^{0}$ & $\%$ & $\mathbf{N}^{0}$ & $\%$ & $n^{0}$ & $\%$ & $n^{0}$ & $\%$ & $\mathrm{n}^{\mathbf{0}}$ & $\%$ \\
\hline \multirow{3}{*}{$\begin{array}{l}\text { Con } \\
\text { pensión }\end{array}$} & Institucional & 11 & 47,83 & 37 & 54,41 & 2 & 66,67 & 4 & 44,44 & 54 & 52,43 \\
\hline & Condicionada & 12 & 52,17 & 31 & 45,59 & 1 & 33,33 & 5 & 55,56 & 49 & 47,57 \\
\hline & Total & 23 & 12,71 & 68 & 19,21 & 3 & 10,71 & 9 & 8,11 & 103 & 15,28 \\
\hline \multicolumn{2}{|c|}{$\begin{array}{l}\text { Coadjutores } \\
\end{array}$} & 12 & 6,63 & 24 & 6,78 & 0 & 0 & 1 & 0,90 & 37 & 5,49 \\
\hline \multicolumn{2}{|c|}{ Sin pensión / Se ignora } & 146 & 80,66 & 262 & 74,01 & 25 & 89,29 & 101 & 90,99 & 534 & 79,23 \\
\hline \multicolumn{2}{|l|}{ Total } & 181 & 100 & 354 & 100 & 28 & 100 & 111 & 100 & 674 & 100 \\
\hline
\end{tabular}

¿Por qué no existe una coincidencia total entre las prebendas apensionadas y la vía condicionada? Por una parte, al asignar la forma de acceso de cada prebendado, no se han tenido en cuenta los derechos de otros candidatos, que no llegaron a tomar posesión y que acabaron renunciando a ellos, en muchos casos, a cambio de una pensión, de algún beneficio o de otros derechos sobre otros beneficios; por otra parte, algunas pensiones no procedían del acuerdo entre la parte resignante y la resignada, sino de una merced papal, con la que cargaba determinada prebenda para favorecer a determinada persona; por último, algunos prebendados "heredaron" las pensiones de sus antecesores. Es decir, las pensiones eran vitalicias, esto es, se concedían durante la vida del perceptor de las mismas, independientemente de que el titular de la prebenda falleciese o renunciase antes de la muerte del pensionado. Esto provocaba, en muchos casos, problemas por retrasos en el pago o simplemente por la imposibilidad del mismo por parte del titular ${ }^{16}$. Tengamos en cuenta que, en ocasiones, las prebendas podían estar cargadas por más de una pensión y que el peso de las mismas sobre el valor de la prebenda podía ser muy elevado. Por ejemplo, la canonjía de Gabriel Rodríguez de Casal de Raros, valorada con bastante seguridad en 48 ducados de oro de cámara (unos 19.200 maravedíes), estaba cargada por tres pensiones, que sumaban unos 15.925 maravedíes, es decir, un $82,94 \%$ del valor de la prebenda. Poca congrua le dejaba este gravamen, pero lo equilibraba gracias a su deanato de Lugo. Peor lo tenía el canónigo Benito Rodríguez, cuya prebenda, valorada en 30 ducados de oro de cámara y que había obtenido permutando unos beneficios parroquiales con el canó-

\footnotetext{
16 Sobre la problemática de las pensiones, véase IRIGOYEN LóPEZ, op. cit. (nota 3), pp. 78-81.
} 
nigo Gaspar de Anaya, estaba cargada con una pensión del valor total de la misma a favor de Juan de Pereira, deán de Salamanca, amigo, si no pariente, de dicho Anaya. Está claro que Benito Rodríguez tenía suficiente patrimonio para sobrevivir y que con tan desventajosa permuta buscaba esencialmente el prestigio social que conllevaba acceder a una canonjía compostelana.

Para hacernos una idea, hemos calculado el valor medio de las mismas respecto al valor medio de las prebendas, cuando las fuentes (bulas de provisión, actas capitulares, escrituras notariales) lo indican, para hallar el porcentaje de uno sobre el otro (tabla 6). Para ello hemos realizado la conversión de las monedas referidas a maravedíes ${ }^{17}$. El valor medio es poco significativo, no tanto por el número de ejemplos utilizados (10 para las dignidades, 12 para las canonjías, uno para las raciones), como por las épocas que refieren, puesto que el valor de las prebendas se incrementa con el paso del tiempo y existe un mayor porcentaje de casos tardíos para las canonjías y raciones que para las dignidades. Eso explica que su valor medio sea inferior al de prebendas inferiores. En todo caso, esta valoración es una estimación, que no pretende reflejar el salario real de cada prebendado, asunto que no trataremos aquí ${ }^{18}$. Lo verdaderamente interesante es el porcentaje que la pensión representa sobre el valor de la prebenda. Dejando al margen el único ejemplo de ración apensionada, el porcentaje es similar entre las dignidades y canónigos, un $46 \%$ : es decir, cerca de la mitad de los emolumentos de estos prebendados no recaían en su propio bolsillo.

Tabla 6. Valor medio anual de las pensiones en función del tipo de prebenda

\begin{tabular}{||l|l|l|l||}
\hline \multicolumn{2}{|c|}{ PREBENDA } & \multicolumn{2}{c||}{ PENSIÓN } \\
\hline Tipología & Valor medio (mrs.) & Valor medio (mrs.) & $\%$ \\
\hline Canónigo & 157.500 & $73.727,08$ & 46,81 \\
\hline Dignidad & 87.690 & 40.953 & 46,70 \\
\hline Racionero & 130.200 & 43.400 & 33,33 \\
\hline Total & 125.130 & $52.693,36$ & 42,11 \\
\hline
\end{tabular}

17 Las monedas empleadas solían ser el ducado de oro de cámara, el ducado de oro español (o ducado de oro largo), el escudo de oro español, el real de plata y el julio. El ducado de oro largo equivalía a 375 maravedíes; el julio romano equivalía al real español, que eran 34 maravedíes; el escudo de oro español valía 350 maravedíes en 1537, 400 maravedíes en 1566 y 1595, y 434 maravedíes en 1609; el ducado de oro de cámara valía 400 maravedíes en 1493 y 1566, 434 maravedíes en 1595 y 474 maravedíes en 1609 (SÁez, Fray Liciniano: Demostración histórica del verdadero valor de todas las monedas que corrían en Castilla durante el reynado del señor Don Enrique IV y de su correspondencia con los del señor D. Carlos V, Madrid, Real Academia de la Historia, 1805, pp. 262-267).

18 En el período 1606-1615, por ejemplo, las canonjías valían realmente 405.280 maravedíes al año, según las hojas de distribuciones (Rey Castelao, O.: El Voto de Santiago en la España Moderna (tesis doctoral parcialmente inédita), Santiago, Universidad, 1984, t. II, p. 695). 


\section{Acumulación de prebendas y promoción interna}

El problema de la acumulación de beneficios en manos de un mismo individuo estuvo presente desde muy antiguo en la Iglesia católica, pero fue el III Concilio de Letrán (1179) el que marcó el inicio de la nueva disciplina canónica sobre la pluralidad o incompatibilidad de los beneficios. A pesar de sus disposiciones y las de otros concilios y papas para disminuirla y acabar con la posesión de oficios incompatibles -incompatibilidad que se resumía en la de tener al mismo tiempo curatos, dignidades o personados-, su cumplimiento cayó en agua de borrajas, sobre todo mediante las dispensas papales. El Concilio de Trento reguló al respecto para que se aplicasen dichos cánones e introdujo otros nuevos, que venían a considerar incompatibles todos los beneficios que requerían residencia personal y a exigir la renuncia de aquellos en el plazo máximo de seis meses, aunque dejaban abierta la posibilidad de unir dos o más beneficios si la congrua no era suficiente para mantener al beneficiado. El problema es que, por un lado, la interpretación de estos cánones podía hacerlos ineficaces, $\mathrm{y}$, por otro, seguían siendo legales las dispensas papales por incompatibilidad.

En lo que a las prebendas capitulares se refiere, la obligación de residencia personal y de oficiar culto era común a todas ellas, si bien, hasta Trento, una parte de las dignidades podía rehuirla legalmente al no tener prebenda anexa o emplear sustitutos en los oficios. Por lo tanto, se debía considerar incompatible poseer dos prebendas que exigiesen asistir al oficio divino a un tiempo o que, por su oficio específico (por ejemplo, el de maestro de capilla) fuese incompatible con el servicio del coro de otra prebenda ${ }^{19}$.

A pesar de la legislación canónica y conciliar, los datos demuestran que en el cabildo de Santiago hubo individuos que llegaron a tener más de una prebenda al mismo tiempo $^{20}$. Para demostrarlo, hemos elaborado la tabla 7 , en la que se ha introducido el número de prebendados que obtuvieron una segunda prebenda catedralicia sin dejar inmediatamente la posesión de la primera. Se han tenido en cuenta todas las poseídas por los capitulares del siglo XVI, incluidas las que obtuvieron en el XV y en el XVII,

Tabla 7. Acumulación de prebendas capitulares en función de la prebenda de origen y la de destino

\begin{tabular}{|l|l|l|l|l|l|l|l|l|l|l|l|l||}
\hline \multirow{2}{*}{ PREBENDA } & \multicolumn{2}{|c|}{ Dignidad } & \multicolumn{2}{|c|}{ Canónigo } & \multicolumn{2}{c|}{ Coadjutor } & \multicolumn{2}{|c|}{ Racionero } & \multicolumn{2}{|c|}{ C. Oficio } & \multicolumn{2}{|c|}{ Total } \\
\cline { 2 - 16 } & $\mathbf{N}^{\mathbf{0}}$ & $\mathbf{\%}$ & $\mathbf{n}^{\mathbf{0}}$ & $\mathbf{\%}$ & $\mathbf{n}^{\mathbf{0}}$ & $\mathbf{\%}$ & $\mathbf{n}^{\mathbf{0}}$ & $\mathbf{\%}$ & $\mathbf{n}^{\mathbf{0}}$ & $\mathbf{\%}$ & $\mathbf{n}^{\mathbf{0}}$ & $\%$ \\
\hline Canónigo & 0 & 82,86 & 4 & 11,43 & 1 & 2,86 & 0 & 0 & 1 & 2,86 & 35 & 52,24 \\
\hline Dignidad & 0 & 9,09 & 19 & 86,36 & 1 & 4,55 & 0 & 0 & 0 & 0 & 22 & 32,84 \\
\hline Racionero & 0 & 33,33 & 3 & 50 & 1 & 16,67 & 0 & 0 & 0 & 0 & 6 & 8,95 \\
\hline C. Oficio & 0 & 100 & 0 & 0 & 0 & 0 & 0 & 0 & 0 & 0 & 2 & 2,98 \\
\hline Coadjutor & 0 & 0 & 0 & 0 & 0 & 0 & 2 & 100 & 0 & 0 & 2 & 2,98 \\
\hline Total & 35 & 52,24 & 26 & 38,81 & 3 & 4,48 & 2 & 2,99 & 1 & 1,49 & 67 & 100 \\
\hline
\end{tabular}

19 ANDRÉ, op. cit. (nota 6), t. III (1848), pp. 123-129.

20 Sobre las prebendas dobles en la Iglesia de Córdoba, véase VÁzQuez LeSmes, op. cit. (nota 3), pp. 82-83. 
pero se han contabilizado como una las de los que disfrutaban de una anexa. En la columna de la izquierda aparece la primera prebenda y en la fila superior la segunda, es decir, la prebenda obtenida más recientemente y la más recientemente acumulada a aquella. Los casos que aquí se agrupan son de los de aquellos prebendados que adquieren una nueva prebenda capitular, manteniendo la primera durante un tiempo; los que renuncian a la nueva prebenda antes de cesar en la primera; y los que mantienen ambas conjuntamente hasta el final (muerte o renuncia).

Como podemos apreciar, las dignidades y después las canonjías son las prebendas que mayoritariamente se acumulan a la prebenda cronológicamente anterior, la cual, a su vez, suele ser una canonjía o una dignidad, por este orden. Sólo en un caso, las canonjías de oficio se acumulan a la prebenda anterior y sólo en tres lo hacen las coadjutorías. En cuanto a la prebenda de origen, son pocos los racioneros registrados que obtienen y acumulan alguna otra prebenda (canonjía, dignidad o coadjutoría, por este orden); por su parte, los canónigos obtienen una dignidad y las dignidades una canonjía en un porcentaje superior al $80 \%$, lo que, en el primer caso, viene a constituir un ascenso encubierto en forma de acumulación.

¿Pero cuántas prebendas llegaron a obtener cada uno de los capitulares dentro de la catedral de Santiago? La tabla 8 nos da la respuesta: más de una cuarta parte de los capitulares compostelanos de la decimosexta centuria tuvieron más de una prebenda a lo largo de su vida (sin contar las prebendas anexas ni las coadjutorías). De ellos, un $70 \%$ tuvieron dos y un $23 \%$ llegaron a tres, pero el récord está en seis, cifra alcanzada por don Lope Sánchez de Ulloa "el Viejo", arcediano de Reina, juez de Luou y canónigo de Santiago hasta en cuatro ocasiones. Esto demuestra que la pertenencia al cabildo aumentaba las posibilidades de obtener una nueva prebenda en la misma institución, en gran medida gracias a las presiones de la propia corporación capitular en la elección de sus nuevos miembros.

Tabla 8. Número de prebendas catedralicias por cada capitular

\begin{tabular}{||l|l|l||}
\hline \multirow{2}{*}{$\mathbf{N}^{\mathbf{0}}$ PREBENDAS } & \multicolumn{2}{|c|}{ CAPITULARES } \\
\cline { 2 - 3 } & $\mathbf{n}^{\mathbf{0}}$ & $\mathbf{\%}$ \\
\hline $\mathbf{1}$ & 363 & 73,78 \\
\hline $\mathbf{2}$ & 89 & 18,09 \\
\hline $\mathbf{3}$ & 30 & 6,10 \\
\hline $\mathbf{5}$ & 7 & 1,42 \\
\hline $\mathbf{4}$ & 2 & 0,41 \\
\hline $\mathbf{6}$ & 1 & 0,20 \\
\hline Total & 492 & 100 \\
\hline
\end{tabular}

De los 129 capitulares que tuvieron más de una prebenda compostelana, algunos las poseyeron al mismo tiempo por acumulación, como ya hemos visto, pero la mayor parte llegaron a ellos bien por sucesión interna sin solución de continuidad, o bien por obtención de una prebenda tiempo después de haber dejado de ser miembro del cabildo. En la tabla 9 se registra el número y porcentaje de prebendados que acceden desde una prebenda (columna de la izquierda) a otra (fila superior), habiendo cesado 
en la posesión de la primera. Se consideran todas y cada una de las prebendas acumuladas por un mismo individuo, no únicamente la primera y la última. El análisis de las tipologías capitulares es altamente significativo: como es lógico, los coadjutores aquí registrados son los que acabaron siendo titulares de la prebenda que servían como tales; salvo casi un 7\% de racioneros que accedieron a otra ración, el resto fueron promovidos directamente a una canonjía (69\%) e incluso a una dignidad o coadjutoría de esta (24\%); los canónigos de oficio apenas denotan movilidad alguna, salvo para obtener otra prebenda de oficio o una canonjía, o para ascender a una dignidad; en cuanto a los canónigos "atitulados", casi un $37 \%$ promocionan a una dignidad, pero la mayoría obtienen otra canonjía (más de un 58\%) o, en casos contados, una ración $(4,62 \%)$, bien por permuta y/o por una resigna beneficiosa económicamente (dotada de pensión o reserva de frutos) o familiarmente (favoreciendo a algún pariente); algo parecido ocurre entre las dignidades que pasan a una canonjía $(28 \%)$ o una ración (4\%), mientras que las que pasan a otra dignidad (64\%) suele ser por promoción a una categoría superior (movilidad vertical) o, sobre todo, por resigna/permuta beneficiosa (movilidad horizontal).

Tabla 9. Sucesión interna del cabildo en función del tipo de prebenda

\begin{tabular}{|c|c|c|c|c|c|c|c|c|c|c|c|c|}
\hline \multirow{2}{*}{ PREBENDA } & \multicolumn{2}{|c|}{ Canónigo } & \multicolumn{2}{|c|}{ Dignidad } & \multicolumn{2}{|c|}{ Racionero } & \multicolumn{2}{|c|}{ C. Oficio } & \multicolumn{2}{|c|}{ Coadjutor } & \multicolumn{2}{|c|}{ Total } \\
\hline & $n^{0}$ & $\%$ & $n^{0}$ & $\%$ & $n^{0}$ & $\%$ & $n^{0}$ & $\%$ & $n^{0}$ & $\%$ & $n^{0}$ & $\%$ \\
\hline Canónigo & 38 & 58,46 & 24 & 36,92 & 3 & 4,62 & 0 & 0 & 0 & 0 & 65 & 41,14 \\
\hline Coadjutor & 22 & 62,86 & 11 & 31,43 & 2 & 5,71 & 0 & 0 & 0 & 0 & 35 & 22,15 \\
\hline Racionero & 20 & 68,97 & 6 & 20,69 & 2 & 6,90 & 0 & 0 & 1 & 3,45 & 29 & 18,35 \\
\hline Dignidad & 7 & 28 & 16 & 64 & 1 & 4 & 1 & 4 & 0 & 0 & 25 & 15,82 \\
\hline C. Oficio & 1 & 25 & 1 & 25 & 0 & 0 & 2 & 50 & 0 & 0 & 4 & 2,53 \\
\hline Total & 88 & 55,70 & 58 & 36,71 & 8 & 5,06 & 3 & 1,90 & 1 & 0,63 & 158 & 100 \\
\hline
\end{tabular}

Para terminar, trataremos de dar una visión global de la carrera capitular de un mismo individuo en Compostela, considerando cuál fue la primera prebenda que obtuvo en su cabildo y cuál fue la última, lo que, en definitiva, nos aclarará el grado de promoción interna de la corporación santiaguesa (tabla 10) ${ }^{21}$. Se han desechado, como es lógico, las coadjutorías y prebendas anexas a dignidades, así como los casos de individuos con una sola prebenda en su vida capitular. A tenor de los resultados, un $26,22 \%$ de los capitulares tienen al final de su carrera capitular una prebenda distinta a la que tenían cuando ingresaron en el cabildo. Los destinos en la carrera interna van en consonancia con la jerarquía de la prebenda hacia la que se promociona: dignidades (poco más de un 58\%) y canonjías (más de un 37\%) se llevan la práctica totalidad del pastel. Por otra parte, cabe destacar el alto porcentaje de individuos que ascienden de prebenda: $93,75 \%$ de los racioneros a canónigos $(56,25 \%)$ iy a dignidades (37,50\%)!; 57,58\% de los canónigos a dignidades; 50\% de los canónigos de oficio a

21 Sobre la promoción interna en otros cabildos peninsulares, puede verse como ejemplo el de Murcia en el siglo XVIII (CÁnovas BotíA, A.: Auge y decadencia de una institución eclesial: el cabildo catedral de Murcia en el siglo XVIII. Iglesia y sociedad, Murcia, Universidad, 1994, pp. 249-252). 
dignidades; en cuanto a las dignidades, sólo un $18,52 \%$ de ellas ascienden a dignidades superiores, lo que se explica por el hecho de que constituyen el techo capitular y las posibilidades de promocionar dentro del cabildo son, por lo tanto, menores. Como ya hemos dicho antes, los casos de movilidad horizontal (obtención de una prebenda de la misma categoría) o incluso de descenso de categoría sugieren acuerdos beneficiosos en lo económico y/o familiar. Los casos de descenso están más vinculados a un interés personal y familiar: el canónigo Gómez Álvarez debió permutar su canonicato por la ración de su sobrino Gonzalo Fernández poco antes de morir; el cardenal Domingo Blanco de Caviedes permutó su cardenalía por el canonicato de Juan de Barros para más tarde permutarlo por un canonicato de Palencia -más cercano a su tierra natal- con Pedro Junco de Posada; el cardenal Antonio de Peralta permutó su cardenalía por la ración de Jorge Varela, para luego permutarla por la parroquia de Santa María Magdalena de Sevilla -más cerca de su tierra natal-, que tenía Gonzalo Rodríguez; el cardenal Pedro González de Almenara perdió su cardenalía por no tener el presbiterado y se mandó que fuera proveído en un canonicato cualquiera, como así fue.

Tabla 10. Promoción interna del cabildo en función del tipo de prebenda

\begin{tabular}{|l|l|l|l|l|l|l|l|l|l|l||}
\hline \multirow{2}{*}{ PREBENDA } & \multicolumn{2}{|c|}{ Dignidad } & \multicolumn{2}{c|}{ Canónigo } & \multicolumn{2}{c|}{ Racionero } & \multicolumn{2}{c|}{ C. Oficio } & \multicolumn{2}{c|}{ Total } \\
\cline { 2 - 13 } & $\mathbf{n}^{\mathbf{0}}$ & $\mathbf{\%}$ & $\mathbf{n}^{\mathbf{0}}$ & $\mathbf{\%}$ & $\mathbf{n}^{\mathbf{0}}$ & $\mathbf{\%}$ & $\mathbf{n}^{\mathbf{0}}$ & $\mathbf{\%}$ & $\mathbf{n}^{\mathbf{0}}$ & $\%$ \\
\hline Canónigo & 38 & 57,58 & 27 & 40,91 & 1 & 1,52 & 0 & 0 & 66 & 51,16 \\
\hline Racionero & 12 & 37,50 & 18 & 56,25 & 2 & 6,25 & 0 & 0 & 32 & 24,81 \\
\hline Dignidad & 23 & 85,19 & 2 & 7,41 & 1 & 3,70 & 1 & 3,70 & 27 & 20,93 \\
\hline C. Oficio & 2 & 50 & 1 & 25 & 0 & 0 & 1 & 25 & 4 & 3,10 \\
\hline Total & 75 & 58,14 & 48 & 37,21 & 4 & 3,10 & 2 & 1,55 & 129 & 100 \\
\hline
\end{tabular}

\section{Relaciones entre prebendados: simonía, vía vondicionada y clientelismo}

La simonía era considerada en la Iglesia como uno de los mayores crímenes, cuando no una herejía. Consiste en la "compra o venta deliberada de cosas espirituales, como los sacramentos y sacramentales, o temporales inseparablemente anejas a las espirituales, como las prebendas y beneficios eclesiásticos" 22 . A lo largo del período medieval fue una de sus principales lacras y contra ella legisló desde el primer momento, especialmente en la Reforma Gregoriana y los Concilios Lateranense II, III y IV. Los sínodos gallegos pre-tridentinos se hicieron eco de estos preceptos conciliares, centrándose sobre todo en la erradicación de la simonía en la administración de los sacramentos y en la compra de órdenes eclesiásticas. Sin embargo, según José Antonio Martínez, este modelo eclesiástico oficial no caminó en la práctica por la misma senda que el modelo real. El motivo fundamental radicaba en la imposibilidad por parte de la jerarquía eclesiástica de garantizar el sustento de sus clérigos, lo cual les conducía a buscarlo por su cuenta ${ }^{23}$. Esto se traducía en prácticas claramente

\footnotetext{
22 Diccionario de la Lengua Española, 22a Edición, Madrid, Espasa Calpe, 2001, P. 2067.

23 Martínez Domínguez, J. A.: Os clérigos na Idade Media, Noia, Editorial Toxosoutos, 2001, pp. 109-116.
} 
simoníacas como la compra de prebendas catedralicias, cuya incidencia debió de ser todavía relativamente importante a finales del siglo $\mathrm{XV}^{24}$. En Santiago tenemos un ejemplo de comienzos de la centuria siguiente: el 22 de septiembre de 1513, León X escribe un documento pontificio dirigido al arcediano de Reina, por el que se absolvía al canónigo Álvaro Gómez del delito de simonía que había practicado cuando obtuvo su canonjía por permutación con Pedro Díaz Tenreiro, mercadeando con su iglesia parroquial de San Pedro de Sayças (= ¿San Pedro de Seixas, Lugo?) y su ración catedralicia, en la que le debió suceder Lope Raposo ${ }^{25}$. A pesar de que el Concilio de Trento volvió a condenar la praxis simoníaca, esta siguió existiendo, si no de forma probada y condenable ${ }^{26}$, sí a través de las principales formas de acceso condicionadas por los beneficiados, susceptibles de pactos ilícitos que permitían la reproducción social de los capitulares y la "patrimonialización" de los beneficios, es decir, las coadjutorías, las resignas y las permutas ${ }^{27}$.

Comencemos por las permutas. Teóricamente consistían en el intercambio voluntario de beneficios entre sus beneficiados con autoridad del prelado o del pontífice. El problema surge cuando lo que se canjeaban eran beneficios desiguales porque solían esconder algún tipo de acuerdo ilegítimo, en el que predominaba el interés material sobre el pastoral, de modo que el beneficiado que recibía el beneficio de menor valor se llevaba alguna contrapartida económica o de otro tipo ${ }^{28}$. Para comprobar dicha desigualdad, hemos elaborado una tabla (tabla 11), en cuya fila superior están los tipos de capitulares compostelanos que acceden a su prebenda por permuta y en la columna izquierda se indica el tipo de beneficio cedido a cambio, que, cuando está localizado fuera de la diócesis compostelana, se registra en negrita. Hay que tener en cuenta que sólo se contabilizan el número de accesos a prebendas capitulares compostelanas por vía de permuta (36), no el número de individuos que participaron en ellas (50), muchos de los cuales no pertenecían al cabildo ${ }^{29}$.

Discriminando los casos en que se desconoce qué es lo que permuta el nuevo prebendado (7), tan sólo en un $20 \%$ del total (6) la categoría beneficial de las prebendas permutadas es la misma, si bien en algún caso se introduce algún elemento relacional

24 Así, por ejemplo, gracias a la visita pastoral del obispo Diego Hurtado de Mendoza (1481), sabemos que fueron acusados de simonía el deán, seis canónigos, un racionero y un capellán de la catedral de Palencia (SÁnchez Herrero, José: "Vida y costumbres de los componentes del cabildo catedral de Palencia a finales del siglo XV", Historia, Instituciones, Documentos, 3 (1976), p. 492).

25 ASV, Registri Laterani, 1289, ff. 359-361v; ACS, IG 478, Actas, Lib. $n^{\circ} 4$, ff. 336-337; AHUS, Protocolos Notariales, Santiago de Compostela, 6, s.f.

26 Como ejemplo puede verse el caso de un proceso por simonía en 1671-1676 por un beneficio en la parroquial giennense de Linares (Higueras MaldonAdo, J.: "Un beneficio eclesiástico, por simonía, en el Linares del siglo XVII", Boletín del Instituto de Estudios Giennenses, 172 (jul.-dic- 1999), t. I, pp. 457-480).

27 Soria Mesa, E.: La nobleza en la España moderna. Cambio y continuidad, Madrid, Marcial Pons, 2007, pp. $157-158$.

28 Estos pactos fueron condenados en numerosos sínodos, pero la permisividad papal hacia las permutas provocó su multiplicación y, con ello, el porcentaje de las que buscaban con los cambios mejorar la condición económica (MARTínez DomíngueZ, op. cit. (nota 23), pp. 83-84).

29 Esto explica que, por ejemplo, los casos en que permutaron su dignidad compostelana por otra dignidad sean impares (3), dado que no se ha computado al individuo que permutó una dignidad de otra catedral. 
Tabla 11. Desigualdad beneficial en las permutas de los capitulares ${ }^{30}$

\begin{tabular}{|l|c|c|c|c|c||}
\hline BENEFICIO & Canónigo & Dignidad & Racionero & C. Oficio & Total \\
\hline Dignidad & $\mathrm{x} \mathrm{x} \mathrm{f}$ & $\mathrm{x} \mathrm{x} \mathrm{x}$ & $\mathrm{x}$ & & 7 \\
\hline Canonjía & $\mathbf{x}$ & $\mathrm{x} \mathrm{f} \mathrm{f} \mathrm{b} \mathrm{b}$ & & $\mathrm{x}$ & 7 \\
\hline Beneficio curado & $\mathrm{x} \mathrm{x} \mathrm{p}$ & & $\mathrm{x} \mathrm{x} \mathrm{p} \mathrm{p}$ & & 7 \\
\hline Ración & $\mathrm{fb}$ pr & $\mathrm{x}$ & & & 4 \\
\hline Beneficio sine cura & $\mathbf{p ~ f}$ & $\mathrm{x}$ & $\mathrm{x}$ & & 4 \\
\hline Canonjía de oficio & $\mathrm{x}$ & & & & 1 \\
\hline \hline Se ignora & $\mathrm{x} \mathrm{x} \mathrm{p} \mathrm{f}$ & & $\mathrm{x} \mathrm{x}$ & & 6 \\
\hline \hline Total & 17 & 10 & 8 & 1 & 36 \\
\hline
\end{tabular}

como el parentesco, que podría ocultar algún acuerdo económico privado. Hemos incluido aquí la permuta de un canonicato por la penitenciaría, que percibía los mismos emolumentos que aquel y ni siquiera era por oposición. En 8 casos $(26,67 \%)$ se permuta una prebenda catedralicia por otra prebenda o beneficio con un valor teóricamente inferior, que se complementa con algún prestimonio o sinecura, con un regreso y/o cargándolo con una pensión a su favor. Los 15 restantes son permutas por beneficios inferiores (12) o superiores (3), sin ningún tipo de añadido económico conocido, que pudiese igualar los valores de ambas partes. No obstante, 5 de ellos se dan entre parientes, lo que podría significar que, simplemente, uno de ellos desea favorecer a la otra como parte de una estrategia de perpetuación familiar. Sin embargo, el conocimiento de las relaciones entre prebendados capitulares, principalmente a través de las escrituras notariales y de los testamentos, nos lleva a pensar que la permuta desigual estuvo precedida de alguna contraprestación o lo estaría en el futuro bajo la careta de la solidaridad familiar. En cualquier caso, no cabe ninguna duda que, al menos en los 10 casos restantes, tuvo que existir algún otro premio o beneficio, económico o no, que justifique tal desigualdad. Es el caso, por ejemplo, del giennense Antonio de Peralta, quien obtuvo la cardenalía vacante por muerte de Pedro Varela en 1575, la permutó en 1578 por la ración compostelana de Jorge Varela, pariente de aquel, $\mathrm{y}$, al cabo de tres meses, permutó dicha ración por el beneficio parroquial de Santa María Magdalena de Sevilla ${ }^{31}$. Es evidente que el factor geográfico fue determinante en estas permutas por la proximidad al lugar de origen de Peralta, pero no explica por sí solo la pérdida económica que suponía pasar de una dignidad de la catedral de Santiago a un beneficio parroquial, aunque fuese de la capital hispalense. A idénticas motivaciones parece deberse la permuta que el vallisoletano Francisco López del

\footnotetext{
$30 \mathrm{x}=$ beneficio; $\mathrm{b}=$ prebenda capitular más beneficio/s; $\mathrm{f}=$ permuta entre familiares

$\mathrm{p}=$ beneficio $\mathrm{y} / \mathrm{o}$ prebenda capitular cargado(s) con pensión/es

$\mathrm{pb}=$ beneficio y prebenda capitular cargado(s) con pensión(es)

$\mathrm{pr}=$ beneficio $\mathrm{y} / \mathrm{o}$ prebenda capitular cargado(s) con pensión/es y regreso

$\mathrm{pf}=$ beneficio $\mathrm{y} / \mathrm{o}$ prebenda capitular cargado(s) con pensión/es; permuta entre familiares

Cuando la prebenda o beneficio principal que se permuta está situado en una diócesis distinta a la compostelana se indica en negrita.

31 ACS, IG 517, Actas, Lib. $n^{\circ}$ 17, ff. $402-406$ y 624-625v; ACS, IG 49, Mayordomía. Libro de cuentas (1536-1578), s.f.
} 
Rincón hizo de su iglesia parroquial de Vilvestre (diócesis de Salamanca) en favor de un tal Pero Peros, a cambio del canonicato compostelano de Alonso de Henao, vecino también de la villa pucelana, quien probablemente obtendría, a su vez, alguna contraprestación de dicho Pero Peros ${ }^{32}$.

En cuanto a las coadjutorías, teóricamente se busca con ellas un sustituto adecuado que supla, cumpliendo con las obligaciones de su prebenda, las carencias del titular, normalmente debidas a su elevada edad y/o mala salud. Hemos analizado las causas que justificaron la obtención de una bula de coadjutoría en aquellos casos en que esta derivó en una toma de posesión por parte de algún prebendado compostelano (tabla 12). Para ello nos hemos servido fundamentalmente de la información proporcionada en las propias bulas y, cuando estas no se han conservado (copias u originales), hemos intentado suplirlas, en lo referente a la vejez argüida, con la edad suministrada por otras fuentes. Lógicamente, en esta circunstancia, no podemos saber si, además, hubo algún otro factor que motivase la coadjutoría.

Tabla 12. Causas de las solicitudes de coadjutorías de los prebendados

\begin{tabular}{|l|l|l|l|l|l|l|l|l||}
\hline \multirow{2}{*}{ CAUSA } & \multicolumn{2}{|c|}{ Dignidades } & \multicolumn{2}{c|}{ Canónigos } & \multicolumn{2}{c|}{ Racioneros } & \multicolumn{2}{c|}{ Total } \\
\cline { 2 - 10 } & $\mathbf{n}^{\mathbf{0}}$ & $\mathbf{\%}$ & $\mathbf{n}^{\mathbf{0}}$ & $\mathbf{\%}$ & $\mathbf{n}^{\mathbf{0}}$ & $\mathbf{\%}$ & $\mathbf{n}^{\mathbf{0}}$ & $\%$ \\
\hline Senectud+enfermedad & 4 & 44,44 & 14 & 43,75 & 0 & 0 & 18 & 42,86 \\
\hline Enfermedad & 2 & 22,22 & 11 & 34,38 & 0 & 0 & 13 & 30,95 \\
\hline Senectud & 3 & 33,33 & 6 & 18,75 & 1 & 100 & 10 & 23,81 \\
\hline Servicio & 0 & 0 & 1 & 3,13 & 0 & 0 & 1 & 2,38 \\
\hline Total & 9 & 100 & 32 & 100 & 1 & 100 & 42 & 100 \\
\hline \hline
\end{tabular}

Salvando los casos en que no hemos hallado información (casi un 15\%), lo normal es que la combinación de senectud y enfermedades constituyesen argumentos suficientes para la concesión de coadjutoría, al margen de la idoneidad del candidato. La edad mínima que se considera en la documentación pontificia lo suficientemente avanzada como para suponer una carga para el servicio en la iglesia compostelana es de 60 años. Sin embargo, la media de los prebendados que obtienen coadjutor no llega a esa cifra $\left(58,85\right.$ en dignidades, 55,43 en canónigos) ${ }^{33}$. Esto quiere decir que tiene que haber alguna otra causa de mayor peso y ahí entra en juego la precaria salud del prebendado. Sólo un $24 \%$ de estos consigue un coadjutor en base a su avanzada edad, pero será en combinación con sus enfermedades el modelo más frecuente (43\%). En un porcentaje muy importante (31\%) se registran los prebendados que, no alcanzando los 60 años, padecen graves males físicos que justifican la necesidad de un sustituto. Esto explica, por ejemplo, que Fernando Ares del Villar, de tan sólo 23 años, que acababa de acceder como titular al canonicato vacante por muerte de Fernando de Corneda "el Viejo" (1543), de quien había sido coadjutor, solicitara coadjutor a los pocos meses en la persona de su sobrino Alonso Ares, de 12 años. Según se recoge en

\footnotetext{
32 ACS, IG 513, Actas, Lib. $n^{\circ}$ 13, f. 44v; ACS, P 19, Protocolos Notariales, ff. 446-447v.

$33 \mathrm{La}$ de los racioneros $(63,5)$ no puede tenerse en cuenta dado lo reducido de la muestra (2 casos).
} 
la bula, estaba enfermo y oprimido casi todo el año por varias enfermedades, por las que residir y servir su prebenda ponía en máximo peligro su salud ${ }^{34}$.

De cualquier manera, la diferencia de edad entre el titular y el coadjutor llegaba de media a los 30 años y la casi práctica totalidad de los coadjutores no superaba los 40 años. Debemos destacar el caso extraordinario de Alonso Fariña, que con 75 años obtiene la coadjutoría del canónigo Gabriel Romero da Costa por los múltiples males padecidos por este (1560). Lo curioso, sin embargo, es que en la propia bula no se dice nada de su avanzadísima edad, probablemente superior a la de su titular. La información la obtenemos por una información de testigos realizada cinco años después, en la que se preguntaba a uno de los testigos si sabía que

es biejo de ochenta años poco más o menos y enfermo de piedra yjada y de reñones y de otras enfermedades, que por la antigua edad que tiene le an suçedido y suçeden, de manera quel sobredicho no puede salir a parte alguna, y el testigo que depone tiene por muy çierto que, si el dicho canónigo Fariña saliese para Valladolid como por Su Majestad es mandado, no bolbiese bibo a esta çiudad, sino hera por graçia de Dios ${ }^{35}$.

En buena lógica, si se hubiese tenido en cuenta su estado de salud, no hubiese sido aceptado como coadjutor. Por lo tanto, ¿cuál pudo ser el factor que determinó a Gabriel Romero para elegirle como suplente en su prebenda? La propia bula nos lo desvela: ambos eran consanguíneos. La fuerza de la sangre es a veces mayor que la del cuerpo ${ }^{36}$.

Fuera de este binomio edad-salud, sólo he encontrado un caso en que se concede coadjutoría a un prebendado joven y saludable: el conocido "economista" Pedro Fernández de Navarrete, quien, con 35 años, recibe en 1599 como coadjutor de su canonjía a Juan Fernández de Castro, de 28, para que sirva su prebenda mientras reside en la Corte para servir como capellán de los reyes y desarrolle una intensa labor como secretario de la realeza y comisionado en Roma por la Corona y la Iglesia compostelana ${ }^{37}$.

Ahora bien, podemos preguntarnos si la gravedad de la carga argumentada por los titulares en las propias bulas se ajustaba a la realidad ${ }^{38}$. Por lo que toca a la longevidad es difícil responder a esta pregunta sin especular, porque las edades aducidas por los capitulares titulares son generalmente aproximativas: "de 50 años o más", "de más de 60 años", "de cerca de 70 años"... son las expresiones más utilizadas, reforzadas en ocasiones por la constatación de que llevaban sirviendo su prebenda durante 20, 30 ó 40 años $^{39}$. De los diez capitulares que esgrimen como fundamen-

\footnotetext{
${ }^{34}$ ACS, IG 512, Actas, Lib. $n^{\circ} 12$, ff. $188 \mathrm{v}-191$.

35 AHUS, Protocolos Notariales, Santiago de Compostela, 328 , f. $299 \mathrm{v}$.

36 ACS, IG 516, Actas, Lib. $n^{\circ} 16$, ff. 116v-119v.

37 Véase sobre su vida, IgLesias Ortega, A.: "Pedro Fernández de Navarrete, un riojano en la catedral de Santiago", Berceo, 138 (jul.-dic- 2000), pp. 91-137.

38 Dicha gravedad estaba más que cuestionada en la provisión de algunas coadjutorías gaditanas a en los siglos XVII y XVIII (Morgado GARCíA, A.: "El alto clero gaditano durante el Antiguo Régimen (1600-1833)", Studia Historica, 16 (1997), pp. 228-229).

39 El canónigo Cristóbal de Soto, por ejemplo, llevaba 39 ó más años sirviendo su prebenda cuando nombraron coadjutor a su sobrino Alonso Vélez de Guevara (ACS, IG 519, Actas, Lib. n 19, ff. 363v-366).
} 
to exclusivo su vejez (60 años en adelante), sólo dos habían cumplido los setenta. Un $40 \%$ de los individuos que fallecieron como capitulares de Santiago ya habían cumplido los sesenta, por lo que es perfectamente comprensible que a dicha edad hubiese prebendados cuya decrepitud y debilidad les hiciese "incómodo" " "grauibus incommodis senectutis") llevar las cargas de su prebenda. Otra cosa sería saber a qué cargas se refieren en las bulas, pues el nivel de vida de un capitular (dignidades y canónigos, específicamente) en el Antiguo Régimen era bastante elevado y sus tareas pastorales no pueden calificarse ni mucho menos como duras ${ }^{40}$. En cualquier caso, las causas concretas para cada individuo se nos escapan, esas que se engloban en la expresión "et ex certis aliis causis animum suum mouentibus cupit". En cuanto a las dolencias, muchas veces no se precisan ("valitudinarius a pluribus infirmitatibus grauatus existit"), aunque se suele incidir en su importancia, en el temor a su agravamiento y en la periodicidad de su afección: a veces (interdum), frecuente (saepe) o continua (continua). En algunos casos se indica que padecía una enfermedad vírica y febril que le impedía soportar el ejercicio de sus deberes como prebendado ("adeo sui corporis viribus destitutus existit"). Probablemente estas estuviesen relacionadas con las inclemencias del tiempo compostelano ("propter ciuitatis compostellani intenperiem"), a las que se alude en dos bulas de 1596, en medio de un largo período sacudido por años lluviosos y fríos, que se sucedieron en Galicia desde $1571^{41}$.

Las ocasiones en que se concretan estas enfermedades suelen ser las típicas de las clases acomodadas, relacionadas sobre todo con la obesidad y el sedentarismo ${ }^{42}$ : la gota (el canónigo Gómez Rodríguez de Casal de Raros padecía en 1548 de "podagra") 43 ; el catarro o rheuma (la "enfermedad de tos" que sufría en 1533 el canónigo Miguel Rodríguez del Villar, quien también alegó una falta parcial de vista) ${ }^{44}$; la calculosis biliar (el canónigo Eliseo de las Alas Villamarín, además de un "pedum dolore", posiblemente debido a la gota, tenía el "morbo ilíaco") ${ }^{45}$; o enfermedades reumáticas o ciáticas (el cardenal Juan Martínez Ternero dice en 1560 que estaba impedido y agravado por múltiples enfermedades, "praesertim tibiarum inflatione ac dolore" ${ }^{46}$. Sólo en un caso se habla claramente de una enfermedad epidémica, la tuberculosis: se trata del canónigo Gabriel Romero da Costa, que en 1560 es agraciado con un coadjutor porque "ipse ex fluxionibus catari in stomacho et pulmonibus a nonnulis annis morbo thysico et lenta febri aliisque corporis infirmitatibus continue affectus [existit] "'

\footnotetext{
40 Véase a este respecto Morgado García, op. cit. (nota 38), pp. 88-93.

41 Gelabert GonzÁlez, J. E.: Santiago y la Tierra de Santiago de 1500 a 1640 (Contribución a la historia económica y social de los territorios de la Corona de Castilla en los siglos XVI y XVII), Sada y A Coruña, Ediciós do Castro, 1982, pp. 19-21.

42 SÁnchez Granjel, L.: La medicina española renacentista, Salamanca, Universidad de Salamanca, 1980, p. 193. Estas dolencias son las que autores como Luis Lobera de Ávila denominó "enfermedades cortesanas" (Lobera De Ávila, L.: Libro de las quatro enfermedades cortesanas, Madrid, Casa de Juan de Ayala, 1544).

43 ACS, IG 514, Actas, Lib. $n^{\circ} 14$, ff. 31v-33v.

44 ASV, Registri Vaticani, 1425, ff. 245v-249v

45 ACS, IG 519, Actas, Lib. $n^{\circ}$ 19, ff. 296-299.

46 ACS, IG 516, Actas, Lib. $n^{\circ} 16$, ff. 109-112v

47 Ibidem, ff. 116v-119v. Sobre esta enfermedad, véase CARmona, J. I.: Enfermedad y sociedad en los primeros tiempos modernos, Sevilla, Universidad de Sevilla, 2005, pp. 131-148.
} 
Los datos han demostrado que en el cabildo compostelano las coadjutorías estaban determinadas en su mayoría por un deseo de favorecer a los parientes. Lo importante era que el titular pudiese seguir disfrutando de las principales rentas y privilegios de la misma a cambio de una porción de sus emolumentos a favor del coadjutor, contribuyendo a las estrategias de fortalecimiento del linaje al que pertenece. Esto explica que aquí, como en otras catedrales, normalmente las bulas de coadjutoría no cuantifiquen los emolumentos del coadjutor, pues al ser un pariente era normal que hubiese estado viviendo en casa del titular y bajo su protección, de ahí que se contentase con acceder al selecto club de los capitulares y devolviese lo invertido por su protector (no sólo en sustento y vestidos, sino también en sufragar los altísimos costes de la expedición de las bulas de coadjutoría) supliendo a su pater familias cuando este lo requiriese a cambio de los interpresentes y poco más. Lo normal era que las cantidades se fijasen por escritura notarial y que en la bula únicamente se indicase la necesidad de garantizar la congrua sustentación del coadjutor, quien debía percibir por su trabajo una parte de los frutos y emolumentos de la prebenda ${ }^{48}$. Por ejemplo, Alonso Vélez de Guevara, canónigo coadjutor desde 1588, recibiría por su trabajo las distribuciones cotidianas, aniversarios manuales y otros emolumentos menores -incluidas lo percibido por tenencias- del valor de la prebenda, que no pasaba de los 700 ducados de oro de cámara ${ }^{49}$. Antes de Trento sólo hemos hallado dos bulas que excepcionalmente cuantifican su salario: son las que en 1541 lograron el cardenal Martín Romero y el canónigo Juan de Buela a favor del hijo del otro en una maniobra de nepotismo cruzado, según las cuales Alonso López de Buela y Fructuoso Romero percibirían la mitad de los frutos de sus respectivas prebendas ${ }^{50}$. Una participación tan elevada sólo puede explicarse como parte de una estrategia familiar muy meditada en la que los titulares y sus coadjutores saldrían muy fortalecidos.

Después del Concilio, sin duda como consecuencia de las medidas tomadas para buscar una mayor transparencia y licitud en las coadjutorías y una mayor garantía de la sustentación del coadjutor, algunas expresan numéricamente los emolumentos a percibir sobre algunas canonjías, valoradas en no más de 600 ducados de oro de cámara: 100 ducados de oro de cámara en 1560; la misma cantidad, más los aniversarios y distribuciones cotidianas, en 1586; 100 ducados españoles en 1594, 1595 y 1596 ; 150 y 200 ducados en 1596 ... Como se puede observar, se produce una progresiva mejora, duplicándose el montante recibido por el coadjutor desde un $14 \%$ hasta un $28 \%$ del valor de la prebenda.

Más allá del parentesco, hubo otros criterios relacionales para solicitar las coadjutorías. El coadjutor puede ser un amigo o un cliente del titular de la prebenda. Esta relación podía proceder de una relación previa dentro del cabildo: por ejemplo, coadjutores que antes de ser capitulares fueron capellanes de la catedral, como Domingo Ruiz de Durana, capellán de las parroquias compostelanas de San Benito del Campo y Santa María del Camino por designación de su tío, el cardenal Juan Ruiz de Durana, luego capellán del coro desde 1589 y que fue coadjutor desde 1596 en la cardenalía

\footnotetext{
48 Véase Irigoyen López, op. cit. (nota 3), pp. 53-56; CABEZA, op. cit. (nota 13), pp. 252-255.

49 ACS, IG 519, Actas, Lib. $n^{\circ}$ 19, ff. 363v-366.

50 ACS, IG 512, Actas, Lib. $n^{\circ} 12$, ff. 115-116v; ACS, IG 513, Actas, Lib. $n^{\circ} 13$, ff. 167-169.
} 
de Pedro de Represa, foráneo como él, con quien desarrolló, sin duda, una relación de dependencia ${ }^{51}$. En algún caso, logramos deducir que hubo una relación de mutua confianza plasmada en los testamentos: el canónigo Álvaro Pérez de Osma Delgado modificó en el último momento un testamento anterior para nombrar como uno de sus albaceas a su coadjutor Gonzalo Barba de Figueroa, sobre el que ejerció su patronazgo $^{52}$. En otros casos, la relación de dependencia es muy clara: Gabriel Botello había sido durante más de veinte años vicario del arcedianato de Salnés regido por Pedro de Torquemada hasta que este le eligió como su coadjutor en $1522^{53}$. También el deseo de favorecer a algún amigo pudo determinar la elección de sucesor en la prebenda: el canónigo Pedro de Vaamonde nombró heredero universal a su amigo, el licenciado Cisneros, abogado de la Real Audiencia de Galicia (años después canónigo lectoral de Decretos), y eligió como coadjutor de su prebenda al hijo de este, Antonio González de Cisneros $(1540)^{54}$.

El mismo tipo de vínculos que hemos visto para las permutas y coadjutorías se puede encontrar en las resignas. Pero el más llamativo es el esquema de clientelismo descrito por Antonio Irigoyen para los coadjutores del cabildo de Murcia en el XVII: un familiar, amigo o cliente de un capitular influyente, que es elegido coadjutor de una prebenda por su titular, el cual, a su vez, mantiene una relación de dependencia respecto a dicho capitular, de manera que tenemos un capitular-patrón, un coadjutorcliente y un titular-cliente, y un modelo relacional en el que lo importante no es quién es el titular de la prebenda ni quién aspira a suceder en ella, sino quién avala al aspirante ${ }^{55}$. Este modelo se puede reproducir en las resignas u otras formas de acceso: un capitular patrón, un sucesor-pariente y un antecesor-cliente.

Es el caso del cardenal Alonso Yáñez Calviño $(+1526)$, de quien sería testamentario su gran amigo y cliente Lope Raposo, el cual accede a las presiones del anterior para favorecer a su sobrino Juan Suárez de Santa Cruz, capellán de la parroquial de San Miguel dos Agros, en quien Raposo renuncia en 1524/1525, por un lado, su ración compostelana para acceder a un canonicato, y, por otro, su beneficio simple de San Lourenzo da Pousada, a cambio de sendas pensiones sobre dicha capellanía y sobre el beneficio con cura de San Martiño de Fontecada, de los que era rector Juan de Santa Cruz (cuadro 1). Queda patente en este ejemplo que, como apunta Antonio Cabeza, en las relaciones de patronazgo, a pesar del desigual estatus del patrón y sus clientes (en este caso, un patrón-dignidad, su cliente-racionero y el cliente de amboscapellán), se desarrolla entre ellos una reciprocidad en la ayuda, de la que todos salen beneficiados ${ }^{56}$.

Una variante de este modelo patrón-pariente-cliente es aquel en el que la prebenda llega a manos de un cliente del capitular-patrón a través de un capitular-pariente. Ejemplo: el chantre Juan Melgarejo resigna su canonicato, su chantría y varios beneficios parroquiales (29 de julio de 1529) en favor de su paisano sevillano García de

\footnotetext{
51 ACS, IG 51, Mayordomía. Libro de cuentas $n^{\circ}$ 3; ACS, IG 520, Actas, Lib. $n^{\circ} 20$, ff. 498v y 500-504v.

52 ACS, IG 124, Colegio de Sancti Spiritus, Fundaciones (1512-1787), nº 3.

53 ACS, IG 480, Actas, Lib. $n^{\circ} 6$, ff. 246v-247v.

54 ACS, IG 512, Actas, Lib. $n^{\circ} 12$, ff. 40-41.

55 Irigoyen López, op. cit. (nota 10), pp. 61-63.

56 CABEZA, op. cit. (nota 15), p. 263.
} 
Cuadro 1. Clientelismo capitular: capitular-patrón, antecesor-cliente y sucesor-pariente

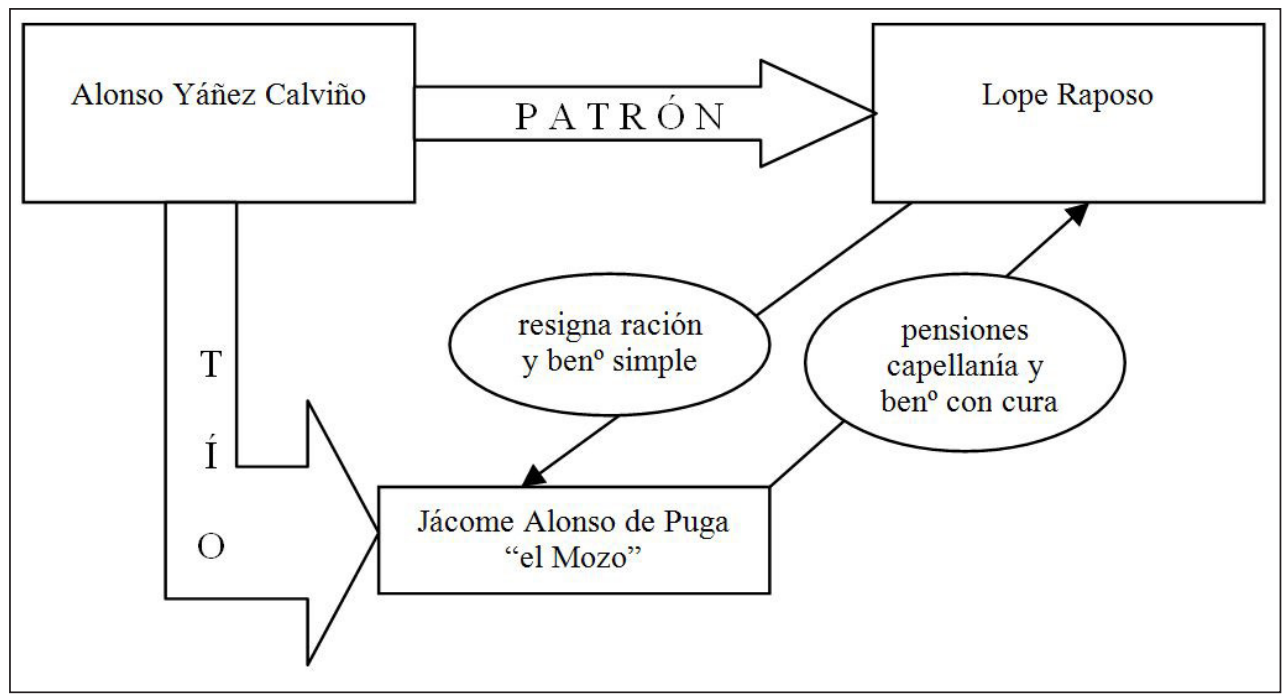

Gibraleón, curial de Roma, que inmeditamente (26 de septiembre) lo resigna en favor de Bernaldino Melgarejo, hijo de aquel, actuando, igual que hizo con otros beneficios y para otros beneficiados, como testaferro del primero. ¿Pero no hubiese sido más fácil resignarla directamente en favor de su hijo? Tal vez los gastos hubiesen sido iguales, sino menores, pero al emplear a un oficial de la curia romana de confianza como intermediario, las garantías de éxito se incrementaban notablemente, sobre todo cuando Juan Melgarejo pretendía reservarse el título de chantre y sus prerrogativas, así como tener el regreso a las dos prebendas capitulares. En cualquier caso, en 1537, Bernaldino Melgarejo resigna dicho canonicato en favor de Jerónimo de Villota, clérigo del beneficio de Santo André de Barciela, que había sido criado de su padre durante muchos años (cuadro 2).

La elección del sucesor también podía ser consecuencia de las relaciones de amistad y clientelismo del prebendado fuera del cabildo. Gonzalo Rodríguez de Villafuerte pertenecía a una linajuda familia de comendadores de la Orden de San Juan de Jerusalén oriundos de La Horcajada (Ávila), pero él se había establecido y casado en Burgos, donde probablemente entró en contacto con su obispo, Juan Álvarez de Toledo, quien se lo llevó a Santiago con el cargo de tesorero y contador arzobispal. Burgalés era también el clérigo Diego de Angulo, a quien el arzobispo trajo a Santiago, donde ejerció como lugarteniente de Villafuerte en su oficio diocesano y obtuvo un canonicato en la catedral. La relación de dependencia de Angulo respecto a Villafuerte se manifestó aún después del fallecimiento del prelado en 1557, concretamente, dos años después, en la resignación de su canonicato en favor de Juan Bautista de Paz, hijo de Villafuerte, quien fue parte activa en la renuncia de la prebenda ante $\mathrm{Su}$ Santidad, actuando como procurador del propio Angulo (cuadro 3). 
Cuadro 2. Clientelismo capitular: capitular-patrón, antecesor-pariente y sucesor-cliente

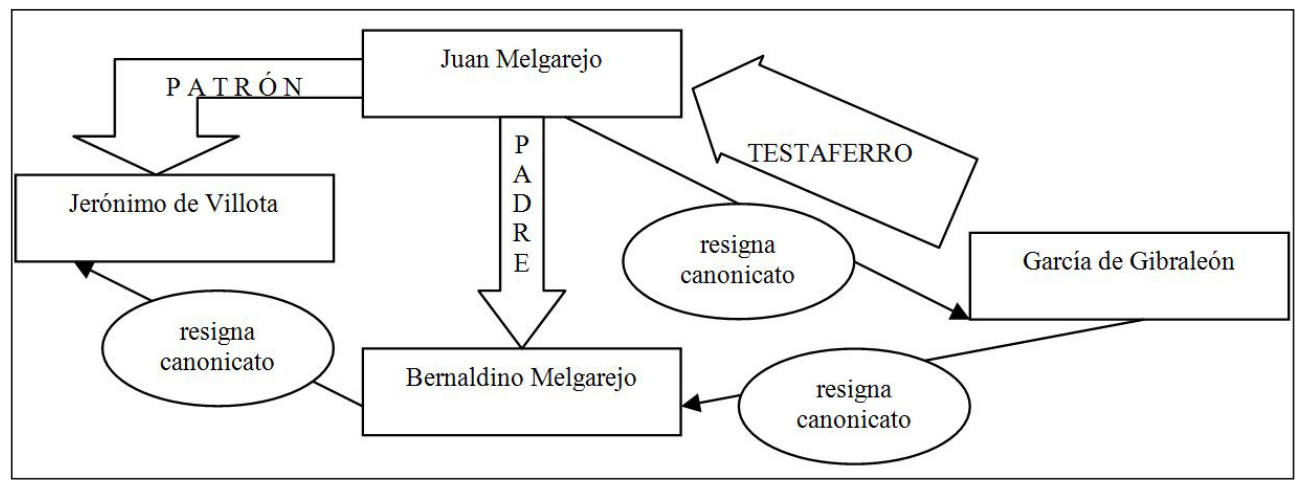

Cuadro 3. Clientelismo capitular: patrón laico, antecesor-capitular y sucesor-pariente

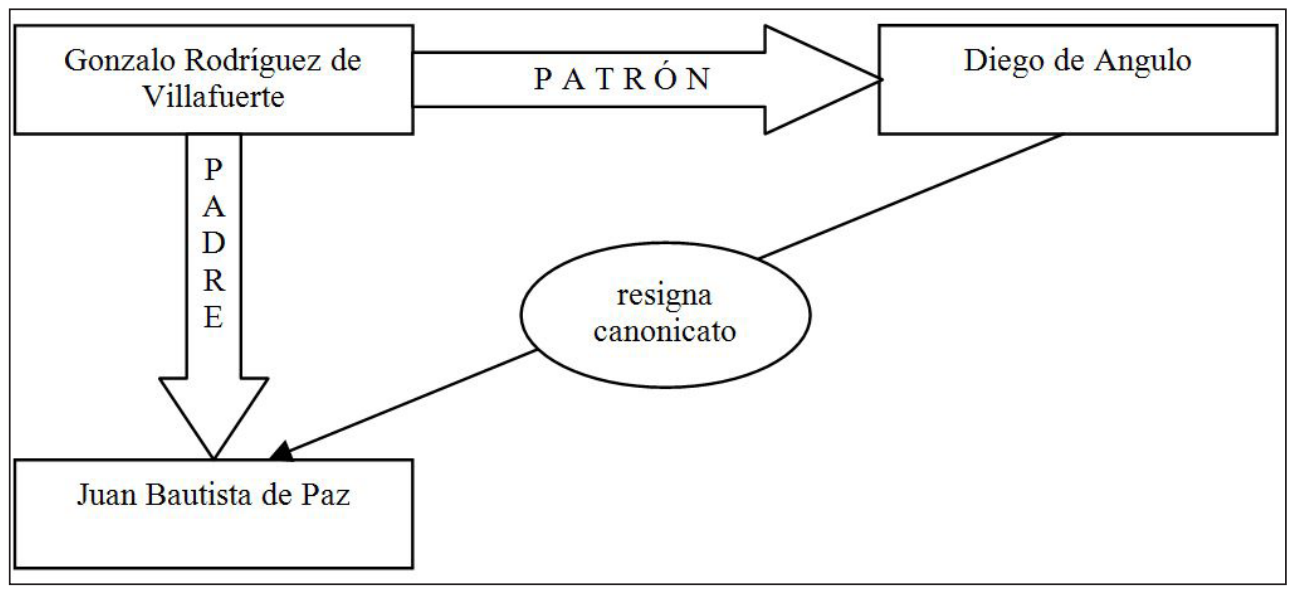

En cuanto a los regresos, se convirtieron en una herramienta para garantizar la posibilidad de retornar a la prebenda resignada siempre que esta quedase vacante $y$, en gran parte de los casos, para reservarse todos o parte de los frutos de la prebenda mediante una pensión compensatoria o una reserva de frutos, de modo que el resignado se convertía en un "hombre de paja" ${ }^{57}$. Este es el caso de Alonso Ares del Villar, quien consiguió anular la posesión de Juan Lorenzo Cebrián en el canonicato que obtuvo por permuta con Fernando Ares del Villar, tío de aquel, empleando una bula de coadjutoría a su favor anterior a la permuta (1544). Finalmente, Ares del Villar y Cebrián se avinieron a una concordia en 1545, en virtud de la cual, dicho Alonso Ares resignó su canonicato en favor de Juan Lorenzo a cambio del regreso y reservación de frutos, pero dejando para la sustentación de Juan Lorenzo

57 Ibidem, pp. 250-251. 
todos los marauedís de los matynes de todo el año eçebto los mareuedís de los matines de las fiestas de Granada y la del Gran Capitán y heçeto la çera que se repartiere entre los benefiçiados y heçeto las bolsas damoderias e syn damoderias, y todo el pan de Conga de todo el año y los mrs. de las proçesiones y fiesta del aniversario del señor cardenal de Toledo y Os y Malpica y salutylafonso y filloas y entradas y entierros de benefiçiados sy los ubiere y otros entrepresentes si los ubiere hasta en cantya de seis reales; y demás y aliende de todo lo sobredicho çincoenta y çinco ducados de oro en cada un año, pagos por los terçios de cada un año de lo que ansy ganare de la dicha prebenda cada un año el dicho Juan Lorenço para el dicho Alonso Arias del Villar de los frutos de la dicha calongía de cada un año ${ }^{58}$.

Al fallecer Cebrián en 1556, Alonso Ares ejecutó el regreso y tomó nueva posesión del canonicato.

Paralelamente o como alternativa se podía mercadear con el derecho a retornar a la prebenda, intercambiándolo por algún otro derecho a su favor o al de algún allegado o pariente. El paradigma en este sentido dentro del cabildo compostelano del Quinientos fue, sin duda, Juan Rodríguez de Ulloa. Miembro del poderoso linaje capitular de los Ulloa, este individuo llegó a ocupar cuatro canonjías y la dignidad de juez de Luou a lo largo de sus 35 años como capitular, lo que le permitió entablar vínculos de todo tipo con otros miembros de la corporación. Para empezar, en 1516 obtuvo el regreso al canonicato de su pariente Juan López de Valladolid, que ya 1levaba casi 30 años sirviendo en él, y en el que le sucedió en 1521. En 1531 obtuvo tres regresos: uno al canonicato que había resignado en favor del maestro Francisco Zapata, scriptor de letras apostólicas y familiar del papa, el cual lo debió resignar o ceder inmediatamente, pero no sabemos en quién acabó; otro al canonicato que resignó en favor de su pariente García Díaz de Mesía; y un último a la cardenalía de Pedro Gil Falcón, quien aceptó conceder dicho regreso y pensión sobre sus frutos para finiquitar el largo pleito que sostuvo con Rodríguez de Ulloa, quien alegaba tener algún derecho a dicha prebenda a través de Gonzalo de Ulloa, antecesor de Gil Falcón en la misma, reservándose el cardenal el derecho a renunciar el beneficio con reserva de frutos por pensión o compensación de tercia parte o mitad. En 1535 debieron hacer un nuevo arreglo porque Pedro Gil eligió a García Díaz de Mesía como coadjutor en su canonicato y se reservó el regreso a favor de Rodríguez de Ulloa. Finalmente, en 1538 obtuvo regreso al canonicato que resignó a favor de Diego Alonso, que quizás fuese su sobrino.

\section{Conclusiones}

Como se ha podido apreciar, por lo general, salvo las vacantes por defunción y la privación de beneficios, todas las demás eran formas susceptibles, de un modo u otro, a la intervención abusiva para la obtención de beneficios capitulares: las dimisiones, porque, al introducir en ellas algún condicionamiento (como la reserva de pensión,

58 ACS, P 20/1, Protocolos Notariales, ff. 307-308. 
de frutos o de regreso), se convertían en resignas encubiertas ${ }^{59}$; las resignas en favor porque, por su propia naturaleza, daban pie al tráfico de prebendas entre el resignante y el resignatario; las permutas (un tipo de traslación), porque suponían el intercambio de beneficios, desiguales o no, entre dos capitulares, por una conveniencia personal ${ }^{60}$; las traslaciones voluntarias, porque no eran sino la renuncia de un beneficio por haber obtenido otro, normalmente mayor (promoción); las expectativas, porque eran un instrumento para garantizar a determinada persona la posesión de un beneficio capitular, normalmente el primero que vacase en dicho cabildo; y las coadjutorías, porque consistían en el nombramiento de un capitular auxiliar de otro con derecho a sucederle cuando su beneficio vacase. Estas dos últimas eran las más viciadas en la práctica, de ahí que el Concilio de Trento prohibiese totalmente las primeras y sólo para casos de urgente necesidad las segundas ${ }^{61}$. Incluso entre las vacantes por defunción, en un buen número de casos se activaban los regresos que se habían gestado durante la titularidad del difunto o justo cuando este la adquirió por la renuncia del que obtenía el regreso futuro a la prebenda. Para complicarlo aún más, las relaciones entre antecesor y sucesor, fundamentalmente de parentesco, inducen a pensar que, detrás de la terminología tan libremente empleada, se esconden renuncias claramente condicionadas.

El análisis estadístico nos ha permitido comprobar que en el cabildo compostelano del XVI predominaba la vía condicionada sobre la institucional, pero que la tendencia se invirtió desde el Concilio de Trento, debido a las medidas aplicadas contra las formas de "patrimonialización" de las prebendas, eliminando las expectativas y los mandatos de providendo y limitando las coadjutorías y resignas, asimilándose así a los valores presentados por cabildos del XVII: la prohibición tridentina de proveer prebendas y beneficios que aún no estuviesen vacantes explica que, mientras en el cabildo compostelano del XVI predominaban las resignas sobre las coadjutorías, en los cabildos del XVII ocurría todo lo contrario, justamente porque se halló en las coadjutorías un subterfugio a la normativa establecida en el Concilio para poder "patrimonializar" las prebendas ${ }^{62}$. Por otra parte, el alto porcentaje de resignas en todas las tipologías capitulares (salvo, como es lógico, las canonjías de oficio) tiene mucho que ver con el altísimo porcentaje -mayor que en los otros cabildos del XVII y XVIII- de prebendados foráneos en Santiago, más interesados en percibir los emolumentos de las prebendas compostelanas y las pensiones cargadas sobre ellas, que en situar a sus familiares y allegados en un cabildo lejano, al que, en muchas ocasiones, no venían a residir (son los "detentadores de rentas catedralicias") ${ }^{63}$. Esto explica que como mínimo un $15 \%$ de las prebendas capitulares estuviesen cargadas con alguna pensión, afectando por igual a las provistas por la vía condicionada como por la institucional, y con una carga media del $46 \%$ de su valor nominal. La mayor parte de estas prebendas apensionadas eran dignidades y canonjías, debido a que sus emolumentos eran lo

59 Véase a este respecto VÁzQuez Lesmes, op. cit. (nota 3), pp. 71-72.

60 Originalmente, las permutas sólo se podían hacer por autoridad del obispo, pero finalmente también acabaron obteniéndose mediante bulas ex causa permutacionis [ANDRÉ, op. cit. (nota 6), t. IV, p. 175].

61 Teruel Gregorio De Tejada, op. cit. (nota 6), pp. 49-50.

62 VÁzQuez Lesmes, op. cit. (nota 3), pp. 73-74.

63 Véase a este respecto lo dicho en IRIGOYen LóPEZ, op. cit. (nota 3), pp. 40-41. 
suficientemente elevados como para derivar una parte hacia una pensión. Por idéntico motivo, también son esas prebendas las que mayoritariamente se acumularon al mismo tiempo en un solo capitular, vulnerando la prohibición canónica y conciliar. La búsqueda de una ventaja económica o social explica igualmente la existencia de casos de movilidad horizontal y de descenso de categoría beneficial.

Los ejemplos más gráficos de prácticas simoníacas se recogen en la vía condicionada de acceso: sólo en un $20 \%$ de las permutas la categoría beneficial de las prebendas intercambiadas era la misma, lo que significa que hubo otros elementos como la solidaridad familiar o regional y la recompensa económica, que justificase tal desigualdad; en algunas coadjutorías parece que la gravedad de la carga argumentada justifica su incomodidad en el desarrollo de las tareas básicas de su prebenda, más que su imposibilidad real, y que criterios relacionales, fundamentalmente el deseo de favorecer a un pariente y de fortalecer el linaje familiar, fueron más determinantes en dicha concesión; las resignas presentan toda una serie de modelos de relación triangular, en los que siempre figura un patrón, un cliente y un pariente, que intercambian prebendas, favores y otro tipo de recursos relacionales; finalmente, los regresos no sólo daban la posibilidad de retornar a la prebenda resignada si esta vacaba y de negociar con ellos para obtener otro derecho o beneficio, sino que, en muchos casos, iban acompañados de una reserva de frutos o de una pensión. 